\title{
Application of Multi-rate Flowing Fluid Electric Conductivity Logging Method to Well DH-2, Tono Site, Japan
}

\author{
Christine Doughty ${ }^{1}$, Shinji Takeuchi ${ }^{2}$, Kenji Amano ${ }^{2}$, Michito Shimo ${ }^{3}$, and Chin-Fu Tsang ${ }^{1}$ \\ ${ }^{1}$ Earth Sciences Division \\ Ernest Orlando Lawrence Berkeley National Laboratory \\ Berkeley, California 94720, USA \\ ${ }^{2}$ Japan Nuclear Cycle Development Institute, Mizunami, Japan \\ ${ }^{3}$ Taisei Corporation, Yokohama, Japan
}

October 2004

\section{Abstract}

In the flowing fluid electric conductivity (FEC) logging method, wellbore fluid is replaced with de-ionized water, following which FEC profiles in the wellbore are measured at a series of times while the well is pumped at a constant rate. Locations were fluid enters the wellbore show peaks in the FEC logs, which may be analyzed to infer inflow strengths and salinities of permeable features intersected by the wellbore. In multi-rate flowing FEC logging, the flowing FEC logging method is repeated using two or more pumping rates, which enables the transmissivities and inherent pressure heads of these features to be estimated as well. We perform multi-rate FEC logging on a deep borehole in fractured granitic rock, using three different pumping rates. Results identify 19 hydraulically conducting fractures and indicate that transmissivity, pressure head, and salinity vary significantly among them. By using three pumping rates rather than the minimum number of two, we obtain an internal consistency check on the analysis that provides a measure of the uncertainty of the results. Good comparisons against static FEC profiles and against independent chemical, geological, and hydrogeological data have further enhanced confidence in the results of the multi-rate flowing FEC logging method. 


\section{Introduction}

In the study of flow and transport through fractured rocks, knowledge of the locations of fractures and their hydraulic properties is essential. Often such knowledge is obtained using deep boreholes penetrating the fractured rock. Various downhole methods of studying fracture flow have been developed over the past few decades (National Research Council, 1996). Coring and geophysical methods may be able to identify the fractures themselves, but they are unlikely to provide information on fracture flow properties. Straddle-packer pump-testing yields fracture flow properties, but it is very time-consuming and expensive. Flow-logging techniques provide an attractive alternative - they are sensitive to fracture flow and are efficient to deploy in the field. Several varieties of flow logging exist, including spinner surveys, heat-pulse flow meters (Paillet and Pedler, 1996; Öhberg and Rouhiainen, 2000), and the flowing fluid electric conductivity (FEC) logging method, also known as hydrophysical logging, which is the technique employed in the present study. Since Tsang et al. (1990) introduced the method, it has been applied in deep wells down to 1500 m or more (Kelly et al., 1991; Guyonnet et al., 1993), in inclined boreholes drilled in the underground Grimsel Test Laboratory (Marschall and Vomvoris, 1995), and extensively in shallower wells down to about $100 \mathrm{~m}$ (Evans et al., 1992; Pedler et al., 1992; Bauer and LoCoco, 1996; Paillet and Pedler, 1996; Karasaki et al., 2000). Continued development of analytical and numerical data-analysis techniques (Löw et al., 1994; Evans, 1995; Doughty and Tsang, 2002; Tsang and Doughty, 2003) have broadened the range of applicability and enhanced the ease of use of the method.

The flowing FEC logging method provides a means to determine hydrologic properties of fractures, fracture zones, or other permeable layers intersecting a borehole in saturated rock. It 
involves replacing the wellbore fluid by de-ionized water and then analyzing the time-evolution of FEC logs obtained while the well is being pumped, yielding information on the locations, inflow strengths, and salinities of permeable features. If flowing FEC logging is repeated using different well pumping rates (a procedure known as multi-rate flowing FEC logging), then the transmissivities and inherent pressure heads of the different permeable features can also be determined (Tsang and Doughty, 2003). Flowing FEC logging requires little or no specialized equipment or expertise, and may be carried out more quickly than most other methods, making it a valuable tool for efficient subsurface characterization.

This paper presents the first field application of the multi-rate flowing FEC logging method, using data from the 500-meter deep well DH-2 in the Tono area of Japan, and thus confirms the method proposed by Tsang and Doughty (2003). Section 2 describes the method; Section 3 shows the field test set-up, measurement procedure, and data; Section 4 explains the analysis steps; Section 5 presents the results, including comparison with available independent data from the Tono site; and Section 6 provides concluding remarks and recommendations.

\section{Method}

\subsection{Data Collection}

In the flowing FEC logging method, the wellbore water is first replaced by de-ionized water or, alternatively, by water of a constant salinity distinctly different from that of the formation water. This is done by passing de-ionized water down a tube to the bottom of the borehole at a given rate, while simultaneously pumping from the top of the well at the same rate. The goal is to completely replace the wellbore water with de-ionized water without pushing any de-ionized water out into the rock formation. Next, the well is shut in or pumped from the top at a constant low flow rate Q (e.g., several or tens of liters per minute), while an electric conductivity probe is 
lowered into the borehole to scan the FEC as a function of depth. This produces what is known as a flowing FEC log. With constant pumping conditions, a series of five or six FEC logs are typically obtained over a one- or two-day period. At depth locations where water enters the borehole (inflow feed points), the FEC logs display peaks. These peaks grow with time and are skewed in the direction of water flow. Figure 1 (Tsang, et al., 1990) shows an example of a set of flowing FEC logs. By analyzing these logs, it is possible to obtain the inflow rates and salinities of groundwater inflow from the individual feed points. Although locations where water leaves the borehole (outflow feed points) do not produce distinct peaks in the FEC logs, they can be identified by their impact on other peaks (Doughty and Tsang, 2002). Recently the flowing FEC logging method has been extended to also determine the inherent pressure heads and transmissivities of the permeable features giving rise to the feed points, by performing flowing FEC logging using different pumping rates, a procedure called multi-rate flowing FEC logging (Tsang and Doughty, 2003).

For the application of multi-rate flowing FEC logging presented in this paper, the feed points into the well represent flows from hydraulically conductive fractures. More generally, they can just as easily represent flow from any permeable zone that intersects the wellbore section being logged (in which case the feed point could be a feed zone with a width). In heterogeneous porous media such as alluvial systems composed of interspersed sand and clay lenses, flow can be just as localized as in fractured rock, and the need for identifying permeable strata just as great.

\subsection{Data Analysis}

The numerical models BORE (Hale and Tsang, 1988) and the enhanced version BORE-II (Doughty and Tsang, 2000) calculate the time evolution of ion concentration (salinity) through 
the wellbore by solving the one-dimensional advection/dispersion equation, given a pumping rate Q and a set of feed-point locations $z_{i}$, strengths $q_{i}$, and salinities $C_{i}$ (i.e., the forward problem). Some analytical solutions are available for FEC profiles obtained from simple feed-point configurations (e.g., Drost et al., 1968; Tsang et al., 1990), but BORE-II broadens the range of applicability of the analytical solutions by considering multiple inflow and outflow feed points, isolated and overlapping FEC peaks, early-time and late-time behavior, time-varying feed-point strengths and salinities, as well as the interplay of advection and dispersion in the wellbore.

The general procedure for using BORE-II is to estimate feed-point locations $z_{i}$ by examining early-time FEC profiles, then assign feed-point properties $\left(q_{i}\right.$ and $\left.C_{i}\right)$ by trial and error until an acceptable match between modeled and observed FEC profiles is obtained (i.e., an inverse problem). If flowing FEC logs were only collected using one pumping rate $Q$, then the analysis ends here. However, if multiple sets of flowing FEC logs are available, the inverse procedure is repeated for each value of $Q$, with the inverse problems constrained by requiring that the same set of $z_{i}$ and $C_{i}$ values be used for each one.

Assuming that two sets of flowing FEC logs were collected with pumping rates $Q_{1}$ and $Q_{2}$, and that the inflow rates from the transmissive fractures as evaluated by BORE-II are $q_{i}^{(1)}$ and $q_{i}^{(2)}$ respectively, then Tsang and Doughty (2003) showed that

$$
\frac{T_{i}}{T_{t o t}}=\frac{q_{i}^{(2)}-q_{i}^{(1)}}{Q_{2}-Q_{1}}
$$

and

$$
\frac{P_{i}-P_{a v g}}{P_{a v g}-P_{w b}^{(1)}}=\frac{q_{i}^{(1)} / Q_{1}}{T_{i} / T_{t o t}}-1
$$


where $T_{i}$ is the transmissivity of fracture $i ; T_{t o t}=\Sigma T_{i}$, which can be obtained by a normal well test over the entire borehole; $P_{i}$ is the inherent pressure head of fracture $i ; P_{\text {avg }}=\Sigma\left(T_{i} P_{i}\right) / T_{\text {tot }}$, which is the pressure in the borehole when it is shut-in for an extended time; and $P_{w b}^{(1)}$ is the pressure drawdown in the wellbore during the flowing FEC logging at $Q=Q_{1}$. We consider the inherent pressure head $P_{i}$ to be the ambient or "far-field" pressure in a fracture or permeable layer that is intercepted by the borehole. $P_{i}$ is the value that would be measured if packers were inflated in the borehole on either side of the fracture to isolate the interval between the packers for a substantial time period to attain steady-state pressure conditions. The derivation of Equations (1) and (2) assumes that the flow geometries within all the hydraulically conductive fractures intercepting the borehole are the same (e.g., all radial flow or all linear flow).

The pressure difference $P_{i}-P_{\text {avg }}$ provides a measure of the driving force for fluid flow between hydraulically conducting fractures and the wellbore under zero-pumping conditions. Note from the definition of $P_{\text {avg }}$ above that if all the $P_{i}$ values are the same, then $P_{i}=P_{\text {avg }}$, and thus there will be no internal wellbore flow under zero-pumping conditions. In this case, Equation (2) shows that feed-point strength $q_{i}$ is proportional to fracture transmissivity $T_{i}$.

The ratios on the left-hand-sides of Equations (1) and (2) are the fundamental results of a multi-rate analysis. If $T_{t o t}, P_{a v g}$, and $P_{w b}$ are also known (say from a conventional well test of the entire well section), then the $T_{\mathrm{i}}$ and $P_{i}$ values themselves can be determined. Additionally, because $T_{i}$ and $P_{i}$ appear in ratios in Equations (1) and (2), if one particular set of $T_{j}$ and $P_{j}$ are measured (say from a well test on a packed-off interval across fracture $j$ ), then all the additional $T_{i}$ and $P_{i}$ values can also be determined.

Tsang and Doughty (2003) denoted the group on the left-hand-side of Equation (2) as the normalized pressure head difference, $(\Delta P)_{n}$. Note that the denominator of $(\Delta P)_{n}$ depends on $Q_{1}$ 
through $P_{w b}^{(1)}$. This $Q$ dependence becomes inconvenient if several pairs of tests using different values of $Q$ are to be compared. Hence, we multiply both sides of Equation (2) by $Q_{1}$

$$
\frac{P_{i}-P_{a v g}}{P_{a v g}-P_{w b}^{(1)}} Q_{1}=\left(\frac{q_{i}^{(1)} / Q_{1}}{T_{i} / T_{t o t}}-1\right) Q_{1}
$$

The ratio $Q_{1} /\left(P_{a v g}-P_{w b}^{(1)}\right)$ is known in the petroleum literature as the productivity index $I$, defined as the ratio of pumping rate to drawdown during a well test. I characterizes the well and the permeable formation it intersects, but is independent of $Q$. Defining $\left(P_{i}-P_{\text {avg }}\right)=\Delta P_{i}$, Equation (3) becomes

$$
I \Delta P_{i}=\left(\frac{q_{i}^{(1)} / Q_{1}}{T_{i} / T_{t o t}}-1\right) Q_{1}
$$

The quantity $I \Delta P_{i}$, provides a measure of inherent pressure head for the $i$ th feed point that is independent of $Q$.

To perform the multi-rate analysis, two sets of FEC logs at two pumping rates (at $Q$ and $2 Q$, for example) are all that is needed. However, if three sets of logs for three pumping rates, $Q_{1}, Q_{2}$ and $Q_{3}$ are available, then three sets of results can be obtained by analyzing three combinations of data: $\left(Q_{1}\right.$ and $\left.Q_{2}\right),\left(Q_{2}\right.$ and $\left.Q_{3}\right)$ and $\left(Q_{3}\right.$ and $\left.Q_{1}\right)$. This provides internal checking, a means to evaluate measurement errors, and an estimate on the confidence level of the analysis results.

\section{Description of Tono Site, Testing Procedure, and Observed Data}

FEC logging was performed in well DH-2 in the Tono area of Gifu Prefecture, Japan (Figure 2). The surface elevation at well DH-2 is $193 \mathrm{~m}$, and the well itself is about $500 \mathrm{~m}$ deep. The upper $167 \mathrm{~m}$ of the well penetrates tertiary sedimentary rocks, which unconformably overly a 
medium-grained biotite granite of Cretaceous age that is weathered and highly fractured.

Lithological logs from deeper wells in the Tono area suggest that at depths greater than several hundred meters, the granite becomes less fractured. The groundwater table is generally close to the ground surface in the Tono area. Well DH-2 is cased only over the sedimentary rock interval. The casing diameter is $118 \mathrm{~mm}$, whereas the open-hole diameter is about $100 \mathrm{~mm}$.

The field instrumentation is shown in Figure 3. Three sets of FEC logs were obtained for three pumping rates $Q$ :

Test $1 Q=10 \mathrm{~L} / \mathrm{min}$ (August 21-22, 2002)

Test $2 Q=20 \mathrm{~L} / \mathrm{min}$ (August 22-23, 2002)

Test $3 Q=5 \mathrm{~L} / \mathrm{min}$ (August $23-24,2002$ )

For each test, a static FEC log was obtained prior to the start of pumping, and then seven FEC logs were measured at one-hour intervals, with pumping maintained at the constant rate. The complete field logging schedule for the three tests is shown in the appendix.

Although the probe collects FEC data while moving both upward and downward through the borehole, only data collected while the probe is moving downward are useful for analysis, due to the configuration of the probe (Figure 3) and the pattern of fluid flow through and past it as it moves. The observed FEC data are shown in Figure 4.

In addition to the FEC logs shown in Figure 4, the water level in the well was also monitored over the period of the three tests. However, the quality of the data is questionable because water levels appear to be inconsistent with pumping rates. Thus water level data were not used in the analysis. Without $P_{a v g}$ and $P_{w b}$, we cannot solve Equations (1) and (2) for the $T_{i}$ and $P_{i}$ values themselves, but we can still obtain $T_{i} / T_{\text {tot }}$ and $I \Delta P_{i}$ for the three tests. 
Later, after our analysis was complete, we received the FEC values of samples taken from different depth intervals in the borehole. These are used as a double-blind test of the FEC values obtained from flowing FEC logging for individual hydraulically conductive fractures. "Doubleblind" means that the two sets of results are obtained from entirely different sets of measurements, both of which are analyzed without knowing the other results.

\section{Analysis}

\subsection{Preliminary Data Processing}

FEC versus depth, and temperature $T$ versus depth profiles were obtained for downward logging once prior to each test ("static profile") and seven times during each test $(0,1,2,3,4,5$, 6 hours after pumping began). The cable speed of the probe, $v$, is assumed to be constant and is inferred from starting and ending times of the logging run and the distance logged. A time is assigned to each (FEC, $z)$ data pair based on $t=t_{\text {start }}+\left(z-z_{\text {start }}\right) / v$.

Temperature correction. Temperature increases with depth from about $23^{\circ} \mathrm{C}$ to $27^{\circ} \mathrm{C}$ over the depth interval of interest between $100 \mathrm{~m}$ and $500 \mathrm{~m}$ below the ground surface, whereas BORE-II considers FEC at a uniform temperature of $20^{\circ} \mathrm{C}$. FEC data collected at various temperatures may be converted to $20^{\circ} \mathrm{C}$ conditions using the formula (Schlumberger, 1984)

$$
\operatorname{FEC}\left(20^{\circ} \mathrm{C}\right)=\operatorname{FEC}(T) /\left[1+S\left(T-20^{\circ} \mathrm{C}\right)\right], \text { with } S=0.024{ }^{\circ} \mathrm{C}^{-1} \text {. }
$$

FEC/Salinity relationship. The FEC/salinity relationship (Hale and Tsang, 1988)

$$
\mathrm{FEC}=1870 C-40 C^{2}
$$


is used to convert feed-point salinities $C(\mathrm{~g} / \mathrm{L})$ to FEC values $(\mu \mathrm{S} / \mathrm{cm})$ within BORE-II and to set up initial salinity conditions for BORE-II.

Choice of initial conditions. Figure 5 shows two early-time FEC profiles for each of the three tests. The FEC profiles labeled "static" were obtained under no-pumping conditions, about two hours after the de-ionization process ended, and about one-half hour before pumping began (see appendix). The presence of peaks in the static FEC profiles indicates that even when the well is not pumped, internal flow occurs in the wellbore, driven by different pressure heads at different depths. Theoretically, we could use the static profiles as initial conditions, model the internal flow for one-half hour, use time-dependent feed-point strengths to represent the onset of pumping, and model the remaining six hours of pumping. However, it is particularly difficult to infer feed-point properties from FEC profiles arising from internal flow, because there is as much invisible outflow as visible inflow. Therefore, we opt to begin modeling at the onset of pumping, using as initial conditions the FEC profiles labeled "flowing" in Figure 5, which were obtained just after pumping commenced. A minor complication is that BORE-II does not expect initial conditions to have a time-variation such as FEC profiles have (e.g., the beginning and ending times of this $\log$ are 8:35 am to 8:51 am for Test 3). So we assign the entire "flowing" profile to an intermediate time (e.g., 8:43 for Test 3) and use it as the initial condition for BOREII.

At the completion of the multi-rate flowing FEC log analysis of Tests 1, 2, and 3, we will be in a good position to analyze the static profiles, because having determined $T_{i} / T_{\text {tot }}$ and $I \Delta P_{i}$ for all the feed points using Equations (1) and (4), we will be able to predict $q_{i}$ when $Q=0$. This procedure is carried out in Section 5.2. 


\subsection{Test 3 BORE-II Analysis}

We start with Test 3, $Q=5 \mathrm{~L} / \mathrm{min}$, because the lowest pumping rate enables individual feed points to be identified most readily. The steps in the matching process are as follows:

- Locate 20 feed points by eye from initial FEC profile

- Categorize feed points as tiny (8 of 20), small (5), medium (6), or large (1)

- Ignore tiny feed points

- Assign $q_{i}$ roughly for small, medium, and large feed points with $\Sigma q_{i}=Q=5 \mathrm{~L} / \mathrm{min}$

- Assign the same $C_{i}$ (denoted $C_{1}$ ) to all the feed points (with $C_{1}$ chosen arbitrarily)

- Run BORE-II

- Correct the order of magnitude of $C_{1}$ by visual inspection of the modeled and observed FEC profiles and run BORE-II again

- Match individual peaks: vary $C_{i}$ and $q_{i}$ values by trial and error, always keeping $\Sigma q_{i}=Q$; run BORE-II; compare modeled and observed FEC profiles; repeat. Add tiny feed points as needed.

The best match to the observed FEC profiles is shown in Figure 6a, followed by plots showing the feed-point strengths (Figure 6b) and salinities (Figure 6c) that produce the match. The ticks in Figure 6a identify 14 feed-point locations, and the semi-circle shows where a wellbore diameter change is inferred (discussed below). Overall, the match between model and observed FEC profiles shown in Figure 6a is considered quite good.

Borehole diameter change at 170-m depth. The diameter of well DH-2 changes at about $170 \mathrm{~m}$ depth, where the well casing ends. The larger wellbore diameter above $170 \mathrm{~m}$ provides a larger cross-sectional area for flow, so for a constant volumetric flow rate, the velocity at which FEC peaks move up the wellbore decreases. Assuming that wellbore fluid is thoroughly mixed 
over the wellbore cross-sectional area, when a peak reaches $170 \mathrm{~m}$ its velocity decreases by a factor $A_{1} / A_{2}$, where $A_{1}$ and $A_{2}$ are the wellbore cross-sectional areas below and above $170 \mathrm{~m}$, respectively. BORE II assumes a constant-diameter wellbore, but the increase in diameter can be accounted for by assigning an outflow feed point at $170 \mathrm{~m}$ with strength equal to $Q\left(1-A_{1} / A_{2}\right)$. Figure 7 shows the shallow FEC profiles predicted for Test 3 for casing diameters of 100, 119, and $127 \mathrm{~mm}$. A 100-mm casing means that the wellbore diameter is constant over the entire well length, and $127 \mathrm{~mm}$ is the value originally reported for the casing diameter. Neither value produces a good fit to the observed FEC profiles above $170 \mathrm{~m}$ depth, but the model results do bracket the data. By trial and error, we find that $118-\mathrm{mm}$ to $119-\mathrm{mm}$ casing diameters yield good fits. Therefore, a 119-mm casing is assumed for all BORE II simulations, by assigning an outflow point with strength $0.3 Q$ at $170 \mathrm{~m}$ depth. Subsequent to our analysis of well DH-2 flowing FEC logs, we obtained a caliper log of well DH-2 that includes the bottom $2 \mathrm{~m}$ of the cased interval, and shows the casing inner diameter to be about $118 \mathrm{~mm}$, equal to the value inferred from BORE II simulations. This exercise demonstrates that the matching of the data with simulation results can unveil small difference in wellbore diameter, and illustrates how the BORE II analysis may be used to check the consistency of information provided about the system.

Sensitivity to dispersion coefficient. The dispersion coefficient used for the BORE-II runs, $D_{0}$ $=0.001 \mathrm{~m}^{2} / \mathrm{s}$, was determined by trial and error along with the feed-point properties. Because $D_{0}$ is orders of magnitude greater than typical molecular diffusion coefficients, there must be a significant amount of dispersion occurring in the wellbore. For $Q=5 \mathrm{~L} / \mathrm{min}$ and a $100-\mathrm{mm}$ diameter wellbore, velocity is $0.01 \mathrm{~m} / \mathrm{s}$. We can convert dispersion coefficient to dispersivity by dividing by velocity, yielding a dispersivity of $0.1 \mathrm{~m}$. This is very reasonable, since we expect 
the dispersivity to be of the order of borehole diameter. Figure 8 illustrates the effect on the FEC profile of increasing and decreasing dispersion coefficient by a factor of 10 . The biggest change occurs around $z=430 \mathrm{~m}$, where several closely spaced feed points with small $q_{i}$ and large $C_{i}$ form an isolated peak. Above $z=320 \mathrm{~m}$, multiple feed points with large $q_{i}$ create a single wide peak, making the profile advection-dominated and nearly independent of $D_{0}$,

Discussion of Test 3 match. When looking at a match between observed and modeled FEC profiles, it is always good to consider how well constrained the corresponding feed-point parameters are. For Test 3, there may be other combinations of flow rate and salinity that would yield a comparably good match. For example, the area under an isolated peak is proportional to the product $q_{i} C_{i}$, making $q_{i}$ and $C_{i}$ inversely related. However, one general conclusion can be made: the $C_{i}$ values for the different feed points cannot all be the same. At the depth of $443 \mathrm{~m}, C$ must be relatively large so that $q$ can be relatively small, in order for the peak to show little skewing with time. At the depths of 275,230 and $205 \mathrm{~m}, C$ must be progressively smaller to get the "stepping down" pattern in the FEC profile.

\subsection{Test 2 BORE-II Analysis}

We next analyze Test 2 , with a pumping rate of $Q=20 \mathrm{~L} / \mathrm{min}$, because with the largest pumping rate of any test, it produces the most different conditions from Test 3 , with the smallest pumping rate. To start the analysis, the $C_{i}$ and $q_{i}$ values are varied to best match the observed FEC profiles, without taking into consideration any of the results of the Test 1 analysis. Four additional feed points are added. The resulting FEC profiles and feed-point properties are shown in Figure 9. For depths greater than $240 \mathrm{~m}$, the match is comparably good to that for Test 1, whereas above $240 \mathrm{~m}$ it is not quite as good. 
We next compare the $C_{i}$ values for Tests 3 and 2 (Figures $6 \mathrm{c}$ and 9c), and argue that changing pumping rate should change $q_{i}$ values but not $C_{i}$ values between tests. Therefore, we recalibrate to Test 3 and Test 2 using same set of $C_{i}$ values for each test. Results are shown in Figures 10 and 11. One additional feed point is added. Several feed-point depths are also adjusted slightly from the analysis of Test 3 , because Test 2 , with its higher $Q$, gives a better indication of locations for fractures with small $q_{i}$. Requiring that the models for both Test 3 and Test 2 use the same $C_{i}$ values worsens the shallow $(z<240 \mathrm{~m})$ match for both tests compared to the previous individual test analyses, but has no adverse effect below that, suggesting that the inferred values of $q_{i}$ and $C_{i}$ for $z>240 \mathrm{~m}$ are more reliable.

\subsection{Test 1 BORE-II Analysis}

To determine the feed-point strengths for Test $1, q_{i}^{(1)}$, we use Equation (1), considering $T_{i} / T_{\text {tot }}$ to be known from $Q_{2}, Q_{3}$, and the $q_{i}^{(2)}$, and $q_{i}^{(3)}$ values obtained from the Test 2 and Test 3 analyses. Solving for $q_{i}^{(1)}$ yields

$$
q_{i}^{(1)}=q_{i}^{(2)}-\frac{T_{i}}{T_{t o t}}\left(Q_{2}-Q_{1}\right)
$$

The resulting FEC profiles are shown in Figure 12 along with the corresponding observed data. The deeper portion of the profile $(z>320 \mathrm{~m})$ shows a good match, whereas in the shallower portion, the model under-predicts the observed FEC values. Figure 12 shows a type of validation test in that it uses results from analyses of Test 2 and Test 3 to predict the results of Test 1 and compare them to Test 1 field data. Overall, the agreement is considered acceptable, as there is no fitting involved. Note that the analyses for Tests 2 and 3 (Figures 10 and 11) showed better matches for the deeper half of the profile than for the shallower half, suggesting 
that the deeper half of the interval is better characterized. Hence, it is not surprising that the match for Test 1 is also better for the deeper half.

\subsection{Combined BORE-II Analysis}

The $q_{i}$ and $C_{i}$ values for all three tests are modified together to simultaneously match all the FEC profiles, using a single set of $C_{i}$ values. The best-match FEC profiles are shown in Figure 13. For $z>320 \mathrm{~m}$, no feed-point changes are needed, as the match for all three tests was already good. For $z<320 \mathrm{~m}$, the updated match for Test 1 is greatly improved (compare Figure 12), the match for Test 2 is slightly worse (compare Figure 11a), and the match for Test 3 is nearly unchanged (compare Figure 10a).

\section{Results and Consistency Tests}

Figure 14 shows the feed-point strengths and salinities used to produce the final match to the FEC profiles for all three tests (Figure 13). Feed-point strength varies between tests as $Q$ changes, but salinity does not.

\subsection{Comparing Pairs of Tests with Different $Q$}

The three tests can be compared two at a time to investigate individual fracture transmissivities and inherent pressure heads using Equations (1) and (4). Because we do not know $T_{t o t}, P_{a v g}$, and $P_{w b}$, we cannot explicitly determine $T_{i}$ and $P_{i}$ values, but the groups $T_{i} / T_{\text {tot }}$ and $I \Delta P_{i}$ provide valuable information on the flow behavior of the fractures relative to one another (Figure 15). 
The combined display of Figure 15 serves three purposes. First, it incorporates all the data collected during the three tests to provide our best estimate for the transmissivity and inherent pressure head of each hydraulically conductive fracture intercepting the borehole. Second, the agreement between different pairs of tests provides a measure of our confidence in the results the better the agreement, the more confident we are. Third, when doing further analyses of the poorly-agreeing feed points, we can tailor our trial choices of $q_{i}$ to minimize the discrepancy between the different test pairs.

For depths greater than $325 \mathrm{~m}$ and for depths between $270 \mathrm{~m}$ and $300 \mathrm{~m}$, the agreement is excellent for both transmissivity and inherent pressure head. Elsewhere, the agreement for transmissivity is good (well within an order of magnitude), but could certainly be better, and the agreement for inherent pressure head is less than satisfactory, pointing out where further analysis efforts should focus. Note that for both quantities, the Test $1 /$ Test 2 analysis and the Test $2 /$ Test 3 analysis agree better with each other than with the Test 3/Test 1 analysis. Hence, when there is a contradiction between results, less credence is given to the Test 3/Test 1 results. Based on the Test $1 /$ Test 2 and Test $2 /$ Test 3 results, there is a trend of increasing inherent pressure head with depth. Not surprisingly, the least certain results are for depths between 300 and $325 \mathrm{~m}$, where $I(\Delta P)_{i}$ changes sign.

Overall, we consider the Test 2/Test 3 results to be the most reliable, in part because for feed points with large discrepancies between the three test pairs, they provide the middle value. Moreover, they do not rely on Test 1 results, which as the first test conducted, may provide less dependable results. Table 1 summarizes the properties of the 19 identified hydraulically conductive fractures as obtained from the combined Tests $2 /$ Test 3 analysis. In this table, $T_{\text {tot }}$ 
and $T_{b a r}$ are the total transmissivity of the wellbore interval from $200-480 \mathrm{~m}$ and the mean transmissivity averaged over the 19 fractures, respectively.

\subsection{Static Profiles}

Recall that the pressure head difference $\left(P_{i}-P_{a v g}\right)$ provides a measure of the driving force for fluid flow between hydraulically conducting fractures and the wellbore under zero-pumping conditions. Figure $15 \mathrm{~b}$ presents $I\left(P_{i}-P_{\text {avg }}\right)=I \Delta P_{i}$ for the 19 hydraulically conductive fractures obtained by our analysis of Test 2 and Test 3. Fractures at depths 287, 298, 304, 318, 323, 347, $366,403,429$ and $440 \mathrm{~m}$ have positive values of $I \Delta P_{i}$, meaning they have pressure heads above the mean shut-in borehole pressure $P_{\text {avg. }}$ This means that at $Q=0$, with no pumping of the borehole, there will be internal flow in the borehole, with inflows coming in from these fractures. Examination of the FEC profiles in the borehole before pumping starts for all three tests (see Figure 5 curves labeled "static"), shows that the FEC peaks occur at depths of about 300, 320, $340,350,365,405,430$, and $440 \mathrm{~m}$, exhibiting very good correspondence to the high- $P_{i}$ feed points.

We can make this comparison quantitative by using BORE II to simulate the zero-pumping period. When $Q=0$, Equation (7) to determine feed-point strength simplifies to:

$$
q_{i}^{(0)}=q_{i}^{(2)}-\frac{T_{i}}{T_{\text {tot }}} Q_{2}
$$

Using Equation (8) and the values from Table 1 to determine $q_{i}^{(0)}$, and taking feed-point salinity values from Figure 14b, we simulate the two-hour period between the time when the de-ionizing equipment was removed from the well and the time when the "static" (zero-pumping) profile was logged for Test 3. Results are shown in Figure 16. Considering that this is a double-blind test, 
we get a remarkably good agreement with the main peaks in the static profile. This provides additional confidence on the correctness of our results. Note that if we had done a zero-pumping simulation using the high- $P_{i}$ feed points predicted by the Test $3 /$ Test 1 pair, we would not have gotten nearly such good agreement (e.g, there would have been static peaks predicted at depths of 205 and $230 \mathrm{~m})$.

\subsection{Comparison to Other Data}

Here, we compare our results with other data collected from well DH-2. None of these data were examined until after the BORE II analyses had been completed. More details on the other data appear in a companion paper that describes the entire suite of hydrogeologic testing performed at the Tono Site (Takeuchi et al., in preparation).

$\underline{C}_{i}$ from measurements on water samples. The measured FEC values (probably of water samples) from short zones of the wellbore were shown to us after our BORE II analyses were complete; they are shown as black lines in Figure 14b. Two black lines are shown at each zone corresponding to FEC values with or without temperature correction. The model reproduces the general trend of increasing salinity with depth correctly, but the model $C_{i}$ values are generally too high. This perhaps can be expected, since the model results give FEC of the fracture water, but water sampling may include wellbore water mixed with it, depending on the sampling method and conditions.

Lithology. The lithostratigraphical column (Figure 17) indicates that the majority of the wellbore interval used for flowing FEC logging, and the locations of all feed points, lie within the Toki granite. The two fault zones noted within the granite correspond to feed-point depths 
identified from FEC peaks (also shown in Figure 17), suggesting that they have hydrological significance.

Fracture density. The fracture density profile (Figure 17) shows numerous fractures distributed over almost the entire borehole length. Some of the depths showing more intense fracturing can be correlated to our identified depths for hydraulically conducting fractures, including depths of 205, 230, 304, 310, 318, 323, 347, 429, 436, 440 and $456 \mathrm{~m}$, which are lithologically identified as fractured zones. Additionally, Figure 17 shows that the depth range from 360 - $400 \mathrm{~m}$ has a low fracture density, and FEC logging identified only two weak feed points within this range (Figure 14). However, the correlation is not perfect. For example, the depth ranges of $170-200 \mathrm{~m}$ and 250 - $300 \mathrm{~m}$ appear quite similar in the fracture density data. In contrast, FEC logging produces no feed points at all within the 170 - $200 \mathrm{~m}$ range, but several moderate-strength feed points in the 250 - $300 \mathrm{~m}$ range (Figure 14). These observations corroborate the notion that fractures with apparently similar geometric properties such as aperture, spacing, and orientation can vary tremendously in their transmissivity, and visual identification of the fractures themselves is not generally sufficient to predict transmissivity.

Alteration. Weathering and alteration_(Figure 17) are typically indicators of large fluid flow, and the two depth intervals within the granite showing the most alteration, 315 - $320 \mathrm{~m}$ and 427 $470 \mathrm{~m}$, correspond to our most significant feed zones.

$\underline{\text { Transmissivity. }}$ Transmissivity measurements (Figure 17) targeted mainly the waterconducting fractures, and indicate that most of these fractures have high transmissivities $\left(10^{-6}\right.$ to $10^{-4} \mathrm{~m}^{2} / \mathrm{s}$ ). Note that low-transmissivity fracture tend to be hard to identify with flowing FEC logging, as their signatures can be swamped by higher transmissivity fractures. The smaller 
range of transmissivities shown in Figure 15a (less than two orders of magnitude) is consistent with this fact.

Based on correlation with results from geological and geophysical investigations, 15 of the 19 feed points identified with flowing FEC logging correspond to major fractures (or fracture zones). For example, borehole radar logging was carried out with a directional radar antenna, with a central frequency of $60 \mathrm{MHz}$. F-K filtering was applied to the raw data to identify reflectors more effectively and precisely. Figure 18 shows mapped reflectors identified with the directional borehole radar technique. These major fractures dip steeply to moderately, and are either E-W trending, N-S trending, or ENE-WSW trending.

\section{Discussion and Conclusions}

By performing the flowing FEC logging method at different pumping rates, we have been able to estimate not only inflow strengths and salinities of hydraulically conductive fractures intersecting the wellbore, but also their transmissivities and inherent pressure heads. Moreover, by using three pumping rates, we obtain a consistency check on the analysis that provides a measure of the uncertainty or our results. Comparisons against static FEC profiles and independent chemical, geological, and hydrogeological data provide further checks on the validity of the multi-rate flowing FEC logging method results.

The present analysis has successfully demonstrated the potential for the flowing FEC logging method as a hydrogeological characterization tool for fractured rock. However, for future applications there are three additional pieces of data that should be collected before or during logging to enable the analysis to be more complete.

1. The quiescent pressure in wellbore $\left(P_{\text {avg }}\right)$. 
2. The water level in the wellbore during pumping $\left(P_{w b}\right)$. These data were collected from well DH-2, but they do not seem consistent with the reported pumping rates, so they need to be checked.

3. The wellbore pressure drop during pumping $\left(P_{a v g}-P_{w b}\right)$. If both $P_{a v g}$ and $P_{w b}$ can be measured, then their difference is obtained automatically. However, if one or the other cannot be measured individually, knowledge of the difference is valuable in itself.

Additionally, it is very important to be able to judge whether the assumption that $\Sigma q_{i}=Q$ is reasonable. When choosing $q_{i}$ by trial and error, the constraint that $\Sigma q_{i}=Q$ greatly expedites the process, but it has been noted at other field sites that large contributions to $Q$ can come from zones beyond the range of FEC logging, invalidating the assumption. For the Test 3 profiles, the evenly spaced FEC fronts enable fluid velocity up the wellbore to be determined, which in conjunction with wellbore diameter, provides an independent measure of $Q$, supporting the assumption that $\Sigma q_{i}=Q$.

Finally, analysis of the DH-2 data, with its significant internal flow under zero-pumping conditions, has made obvious the need for a better means of assigning initial conditions for BORE II. For cases in which internal flow is small or absent, static profiles will be nearly uniform in space and time with small or zero FEC, and will provide suitable initial conditions for BORE II. However, when internal flow is significant, both "static" $(Q=0)$ and flowing $(\mathrm{Q} \neq 0)$ profiles change with time. Since the probe takes a finite amount of time to complete a profile, using any measured FEC profile as an initial condition is problematic in that the timedependence of the profile is lost. The successful static-profile analysis presented in Section 5.2 suggests that after a preliminary multi-rate analysis using flowing FEC logs is done, we may be in a position to do a complete BORE II simulation including both the static and pumping periods. 
In such a complete simulation, we would use a uniform or nearly uniform initial condition (e.g., Figure 16) and match all the static and flowing FEC profiles, instead of assuming any of them as initial conditions.

Now that the flowing FEC logging results have been compared with each other and other independent data, we can clearly see the need to improve the shallow match. Possible ways to improve it include increasing $C_{i}$ for shallow feed points, to correspond to values from water sampling (Figure 14b). We expect that all matches will be improved by such considerations.

In general, using a variety of techniques for hydrogeological characterization is preferable to using just one. The strengths and weaknesses of different methods complement each other, providing a much more reliable picture of the subsurface, particularly for heterogeneous or fractured media. Our primary purpose in performing flowing FEC logging without making use of other data sources was to demonstrate and highlight its capabilities to efficiently determine flow rate, salinity, transmissivity, and inherent pressure head of hydraulically conductive fractures. Having done so, we are now in a good position to integrate all available data to improve our estimates of these quantities.

\section{Acknowledgments}

The reviews of this paper by Barry Freifeld and Curt Oldenburg of Lawrence Berkeley National Laboratory are greatly appreciated. We thank the Geophysical Surveying Company, Ltd., Japan, and in particular Kiyoyuki Matsuoka, for conducting the field logging operations. This work was jointly supported by the Director, Office of Science, Office of Basic Energy Sciences, Geoscience Program of the U.S. Department of Energy, the Taisei Corporation of Japan and by Japan Nuclear Development Cycle Institute (JNC), under the Binational Research 
Cooperative Program between JNC and U.S. Department of Energy, Office of Environmental Management, Office of Science and Technology (EM-50). The work was performed under Contract No. DE-AC03-76SF00098.

\section{References}

Bauer, G.D. and J.J. LoCoco, Hydrogeophysics determines aquifer characteristics, International Ground Water Technology, 12-16, August/September, 1996.

Doughty, C. and C.-F. Tsang, BORE II - A code to compute dynamic wellbore electrical conductivity logs with multiple inflow/outflow points including the effects of horizontal flow across the well, Rep. $L B L-46833$, Lawrence Berkeley National Laboratory, Berkeley, CA, 2000.

Doughty, C. and C.-F. Tsang, Inflow and Outflow Signatures in Flowing Wellbore ElectricalConductivity Logs, Rep. LBNL-51468, Lawrence Berkeley National Laboratory, Berkeley, CA, 2002.

Drost, W., D. Klotz, A. Koch, H. Moser, F. Neumaier, and W. Rauert, Point dilution methods of investigating ground water flow by means of radioisotopes, Water Resources Res., 4(1), 125-146, 1968.

Evans, D.G., Inverting fluid conductivity logs for fracture inflow parameters, Water Resour. Res., 31(12), 2905-2915, 1995.

Evans, D.G., W.P. Anderson, Jr., and C.-F. Tsang, Borehole fluid experiments near salt contamination sites in Maine, in proceedings of the NGWA Conference on Eastern Regional Ground Water Issues, Boston, 797-807, 1992. 
Hale, F.V. and C.-F. Tsang, A code to compute borehole conductivity profiles from multiple feed points, Rep. LBL-24928, Lawrence Berkeley Laboratory, Berkeley, Calif., 1988.

Guyonnet, D., A. Rivera, S. Löw and N. Correa, Analysis and synthesis of fluid logging data from Wellenberg boreholes SB1, SB3, SB4 and SB6, Nagra Tech. Rep. NTB 92-01, pp. 153, Nagra, Wettington, Switzerland, 1993.

Karasaki, K., B. Freifeld, A. Cohen, K. Grossenbacher, P. Cook, and D. Vasco, A multidisciplinary fractured rock characterization study at Raymond field site, Raymond, CA, J. of Hydrology, 236, 17-34, 2000.

Kelly, V. A., J. M. Lavanchy, and S. Löw, Transmissivities and heads derived from detailed analysis of Siblingen 1989 fluid logging data, Nagra Tech. Rep. NTB 90-09, pp. 184, Nagra, Wettington, Switzerland, 1991.

Löw, S., V. Kelley, and S. Vomvoris, Hydraulic borehole characterization through the application of moment methods to fluid conductivity logs, J. App. Geophys., (31(1-4), 117-131, 1994.

Marschall, P. and S. Vomvoris (editors), Grimsel Test Site: Developments in hydrotesting, fluid logging and combined salt/heat tracer experiments in the BK Site (Phase III), Nagra Tech. Rep. 93-47, Nagra, Wettingen, Switzerland, 1995.

National Research Council, Committee on Fracture Characterization and Fluid Flow, Rock fractures and fluid flow: contemporary understanding and applications, National Academy Press, Washington, D.C., 1996.

Öhberg, A. and P. Rouhiainen, Groundwater flow measuring techniques, Posiva 2000-12, Posiva Oy, Helsinki, Finland, 2000. 
Paillet, F.L. and W.H. Pedler, Integrated borehole logging methods for wellhead protection applications, Engineering Geology, 42(2-3), 155-165, 1996.

Pedler, W.H., C.L. Head, and L.L. Williams, Hydrophysical logging: A new wellbore technology for hydrogeologic and contaminant characterization of aquifers, National Outdoor Action Conference, National Ground Water Association, Las Vegas, Nevada, 1992.

Schlumberger, Ltd., Log interpretation charts, New York, 1984.

Takeuchi, S., K. Amano, and M. Shimo, Integrated hydrogeologic investigation in a fractured rock, in preparation.

Tsang, C.-F., P. Hufschmeid, and F.V. Hale, Determination of fracture inflow parameters with a borehole fluid conductivity logging method, Water Resour. Res., 26(4), 561-578, 1990.

Tsang, C.-F. and C. Doughty, Multirate flowing fluid electric conductivity logging method, Water Resour. Res., 39(12), 1354, 2003. 


\section{Appendix: Field Logging Schedule}

\begin{tabular}{|c|c|c|c|c|}
\hline \multirow{2}{*}{\multicolumn{2}{|c|}{$\frac{\text { Activity }}{\text { Time }}$}} & \multirow{2}{*}{\multicolumn{2}{|c|}{$\begin{array}{c}\text { Measurement } \\
\text { Time }\end{array}$}} & \multirow{3}{*}{ Description } \\
\hline & & & & \\
\hline Start & End & Start & End & \\
\hline \multicolumn{2}{|l|}{$8 / 21$} & & & \\
\hline 8:00 & $8: 30$ & & & Site preparation \\
\hline $8: 30$ & 12:00 & & & Install EC logging tools and tubing (tubing bottom at $493.8 \mathrm{~m} *$ ) \\
\hline $12: 00$ & $12: 40$ & & & Install pump and water-level sensor (pump at $49.9 \mathrm{~m}$, sensor at $45.9 \mathrm{~m}$ ) \\
\hline 13:32 & $8: 53 * *$ & & & Replace borehole water with de-ionized water (Circulation \#1) \\
\hline \multicolumn{2}{|l|}{$8 / 22$} & & & \\
\hline $8: 55$ & $9: 15$ & & & Remove pump \\
\hline \multirow[t]{3}{*}{$9: 21$} & $10: 42$ & & & Remove EC logging tools and tubing \\
\hline & & $9: 21$ & $10: 35$ & EC Measurement (STATIC UP) \\
\hline & & $10: 49$ & $11: 25$ & EC Measurement (STATIC DOWN) \\
\hline 11:40 & $12: 00$ & & & Install pump and water-level sensor (pump at $50.2 \mathrm{~m}$, sensor at $46.2 \mathrm{~m}$ ) \\
\hline \multirow[t]{15}{*}{ 12:09 } & $19: 25$ & & & Pumping at $Q=10 \mathrm{~L} / \mathrm{min}$ \\
\hline & & $12: 13$ & $12: 30$ & EC Measurement $(\mathrm{Q}=10 \mathrm{~L} / \mathrm{min}, \mathrm{t}=0 \mathrm{hr}$ DOWN $)$ \\
\hline & & $12: 30$ & $12: 44$ & EC Measurement $(\mathrm{Q}=10 \mathrm{~L} / \mathrm{min}, \mathrm{t}=0 \mathrm{hr} \mathrm{UP})$ \\
\hline & & 13:09 & $13: 24$ & EC Measurement $(\mathrm{Q}=10 \mathrm{~L} / \mathrm{min}, \mathrm{t}=1 \mathrm{hr}$ DOWN $)$ \\
\hline & & $13: 25$ & $13: 41$ & EC Measurement $(\mathrm{Q}=10 \mathrm{~L} / \mathrm{min}, \mathrm{t}=1 \mathrm{hr} \mathrm{UP})$ \\
\hline & & 14:09 & $14: 25$ & EC Measurement $(\mathrm{Q}=10 \mathrm{~L} / \mathrm{min}, \mathrm{t}=2 \mathrm{hr}$ DOWN $)$ \\
\hline & & $14: 25$ & $14: 40$ & EC Measurement $(\mathrm{Q}=10 \mathrm{~L} / \mathrm{min}, \mathrm{t}=2 \mathrm{hr} \mathrm{UP})$ \\
\hline & & 15:09 & $15: 25$ & EC Measurement $(\mathrm{Q}=10 \mathrm{~L} / \mathrm{min}, \mathrm{t}=3 \mathrm{hr} \mathrm{DOWN})$ \\
\hline & & $15: 25$ & $15: 40$ & EC Measurement $(\mathrm{Q}=10 \mathrm{~L} / \mathrm{min}, \mathrm{t}=3 \mathrm{hr} \mathrm{UP})$ \\
\hline & & 16:09 & $16: 25$ & EC Measurement $(\mathrm{Q}=10 \mathrm{~L} / \mathrm{min}, \mathrm{t}=4 \mathrm{hr}$ DOWN $)$ \\
\hline & & $16: 25$ & $16: 40$ & EC Measurement $(\mathrm{Q}=10 \mathrm{~L} / \mathrm{min}, \mathrm{t}=4 \mathrm{hr} \mathrm{UP})$ \\
\hline & & 17:09 & $17: 25$ & EC Measurement $(\mathrm{Q}=10 \mathrm{~L} / \mathrm{min}, \mathrm{t}=5 \mathrm{hr} \mathrm{DOWN})$ \\
\hline & & $17: 25$ & 17:41 & EC Measurement $(\mathrm{Q}=10 \mathrm{~L} / \mathrm{min}, \mathrm{t}=5 \mathrm{hr} \mathrm{UP})$ \\
\hline & & 18:09 & $18: 25$ & EC Measurement $(\mathrm{Q}=10 \mathrm{~L} / \mathrm{min}, \mathrm{t}=6 \mathrm{hr} \mathrm{DOWN})$ \\
\hline & & 18:25 & $18: 41$ & EC Measurement $(\mathrm{Q}=10 \mathrm{~L} / \mathrm{min}, \mathrm{t}=6 \mathrm{hr} \mathrm{UP})$ \\
\hline 19:25 & $19: 45$ & & & Remove pump \\
\hline 19:55 & $21: 25$ & & & Install EC logging tools and tubing (tubing bottom at $488.8 \mathrm{~m}$ ) \\
\hline $21: 25$ & $22: 00$ & & & Install pump and water-level sensor (pump at $50.2 \mathrm{~m}$, sensor at $46.2 \mathrm{~m}$ ) \\
\hline $22: 17$ & $8: 34 * *$ & & & Replace borehole water with de-ionized water (Circulation \#2) \\
\hline
\end{tabular}




\begin{tabular}{|c|c|c|c|c|}
\hline \multicolumn{5}{|l|}{$8 / 23$} \\
\hline $8: 35$ & 9:08 & & & Remove pump \\
\hline \multirow[t]{3}{*}{ 9:08 } & 9:58 & & & Remove EC logging tools and tubing \\
\hline & & 9:09 & $9: 56$ & EC Measurement (STATIC UP) \\
\hline & & $10: 08$ & $10: 26$ & EC Measurement (STATIC DOWN) \\
\hline 10:40 & 11:00 & & & Install pump and water-level sensor (pump at $50.2 \mathrm{~m}$, sensor at $46.2 \mathrm{~m}$ ) \\
\hline \multirow[t]{4}{*}{ 11:02 } & $17: 56$ & & & Pumping at $Q=20 \mathrm{~L} / \mathrm{min}$ \\
\hline & & 11:09 & $11: 25$ & EC Measurement $(\mathrm{Q}=20 \mathrm{~L} / \mathrm{min}, \mathrm{t}=0 \mathrm{hr} \mathrm{DOWN})$ \\
\hline & & $11: 25$ & $11: 42$ & EC Measurement $(\mathrm{Q}=20 \mathrm{~L} / \mathrm{min}, \mathrm{t}=0 \mathrm{hr} \mathrm{UP})$ \\
\hline & & 12:02 & $17: 35$ & Repeat down and up measurements at one hour intervals for 6 hours \\
\hline 18:00 & $18: 30$ & & & Remove pump \\
\hline 18:30 & $19: 30$ & & & Install EC logging tools and tubing (tubing bottom at $488.8 \mathrm{~m}$ ) \\
\hline 19:30 & $19: 58$ & & & Install Pump and water-level sensor (pump at $50.2 \mathrm{~m}$, sensor at $46.2 \mathrm{~m}$ ) \\
\hline 20:12 & $6: 28 * *$ & & & Replace borehole water with de-ionized water (Circulation \#3) \\
\hline \multicolumn{5}{|l|}{$8 / 24$} \\
\hline $6: 30$ & $6: 45$ & & & Remove pump \\
\hline \multirow[t]{3}{*}{$6: 48$} & $7: 34$ & & & Remove EC logging tools and tubing \\
\hline & & 06:48 & 07:33 & EC Measurement (STATIC UP) \\
\hline & & $07: 43$ & 08:00 & EC Measurement (STATIC DOWN) \\
\hline $8: 17$ & $8: 32$ & & & Install pump and water-level sensor (pump at $50.2 \mathrm{~m}$, sensor at $46.2 \mathrm{~m}$ ) \\
\hline \multirow[t]{4}{*}{$8: 32$} & $15: 16$ & & & Pumping at $Q=5 \mathrm{~L} / \mathrm{min}$ \\
\hline & & 08:35 & 08:51 & EC Measurement $(\mathrm{Q}=5 \mathrm{~L} / \mathrm{min}, \mathrm{t}=0 \mathrm{hr}$ DOWN $)$ \\
\hline & & 08:52 & 09:10 & EC Measurement $(\mathrm{Q}=5 \mathrm{~L} / \mathrm{min}, \mathrm{t}=0 \mathrm{hr} \mathrm{UP})$ \\
\hline & & 09:32 & $15: 15$ & Repeat down and up measurements at one hour intervals for 6 hours \\
\hline
\end{tabular}

*numbers refer to depth below the ground surface

**the next morning 
Table 1. Information on hydraulically conducting fractures, based on combined analysis of Test 2 and Test 3.

\begin{tabular}{|c|c|c|c|c|c|}
\hline Depth (m) & $\begin{array}{c}q_{i}^{(2)} \\
(\mathrm{L} / \mathrm{min})\end{array}$ & $\begin{array}{c}q_{i}^{(3)} \\
(\mathrm{L} / \mathrm{min})\end{array}$ & $\frac{T_{i}}{T_{t o t}}$ & $\frac{T_{i}}{T_{b a r}}$ & $\begin{array}{c}I \Delta P_{i} \\
(\mathrm{~L} / \mathrm{min})\end{array}$ \\
\hline 205 & 2.45 & 0.473 & 0.132 & 2.504 & -1.42 \\
\hline 230 & 1.55 & 0.325 & 0.082 & 1.552 & -1.02 \\
\hline 250 & 1.25 & 0.200 & 0.070 & 1.330 & -2.14 \\
\hline 275 & 0.50 & 0.000 & 0.033 & 0.633 & -5.00 \\
\hline 287 & 0.60 & 0.175 & 0.028 & 0.538 & 1.18 \\
\hline 298 & 2.10 & 0.650 & 0.097 & 1.837 & 1.72 \\
\hline 304 & 1.70 & 0.500 & 0.080 & 1.520 & 1.26 \\
\hline 310 & 1.30 & 0.250 & 0.070 & 1.330 & -1.42 \\
\hline 318 & 2.00 & 0.550 & 0.097 & 1.837 & 0.68 \\
\hline 323 & 2.80 & 0.750 & 0.137 & 2.597 & 0.48 \\
\hline 331 & 0.10 & 0.015 & 0.006 & 0.108 & -2.36 \\
\hline 338 & 0.50 & 0.125 & 0.025 & 0.475 & 0.00 \\
\hline 347 & 0.50 & 0.175 & 0.022 & 0.412 & 3.08 \\
\hline 366 & 0.20 & 0.075 & 0.008 & 0.158 & 4.00 \\
\hline 403 & 0.20 & 0.080 & 0.008 & 0.152 & 5.00 \\
\hline 429 & 1.10 & 0.300 & 0.053 & 1.013 & 0.62 \\
\hline 436 & 0.75 & 0.187 & 0.038 & 0.713 & -0.02 \\
\hline 440 & 0.32 & 0.150 & 0.011 & 0.215 & 8.24 \\
\hline 456 & 0.08 & 0.020 & 0.004 & 0.076 & 0.00 \\
\hline \multirow[t]{2}{*}{$\begin{array}{c}\text { Entire } \\
\text { wellbore }\end{array}$} & 20 & 5 & 1 & $1 / 19$ & \\
\hline & & & gure 1 & & Figure $15 b$ \\
\hline
\end{tabular}




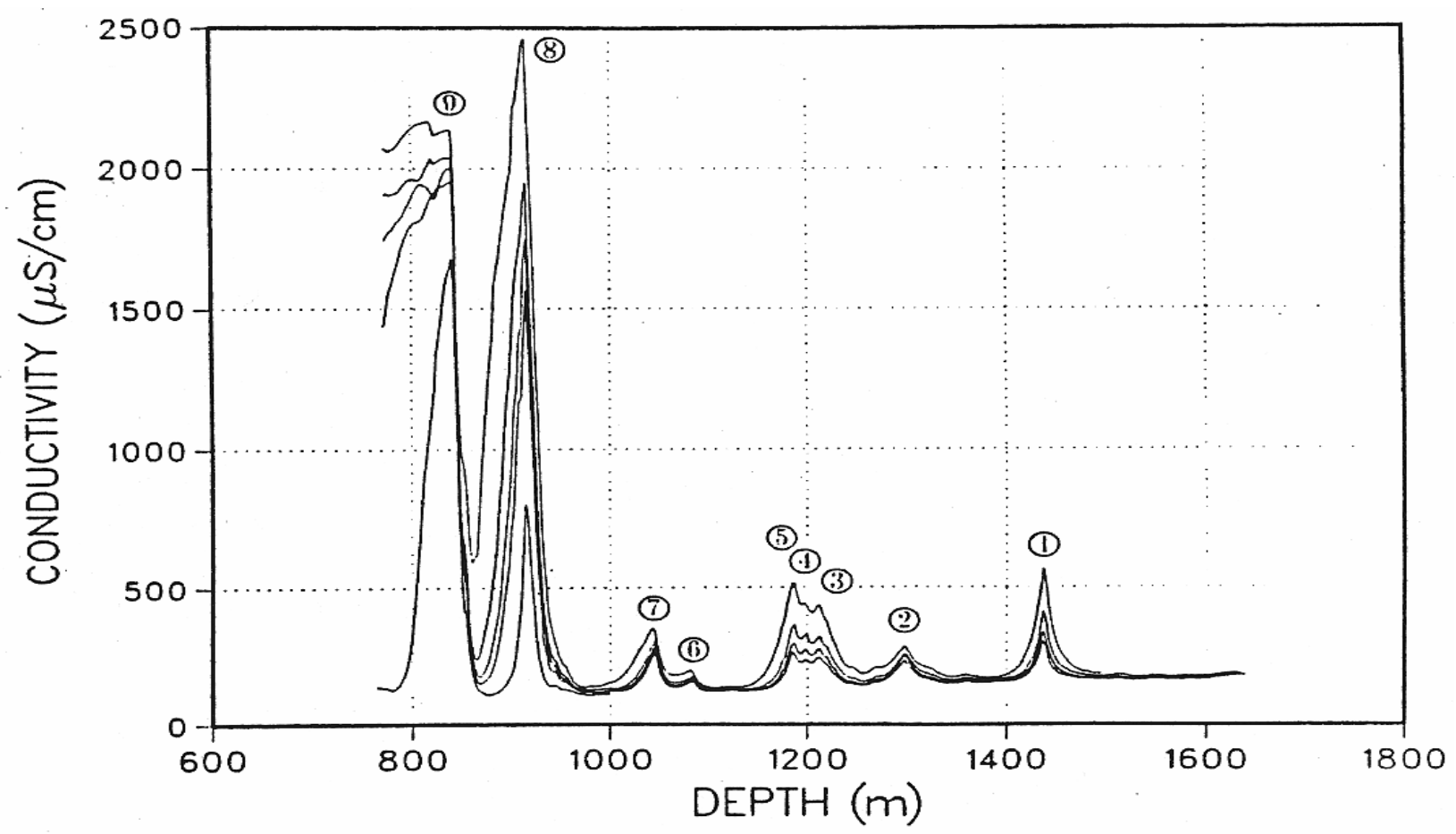

Figure 1. FEC for the $770 \mathrm{~m}$ to $1610 \mathrm{~m}$ logged section of the $1690 \mathrm{~m}$ deep Leuggern borehole in northern Switzerland (Tsang et al., 1990). The circled numbers identify feed points. 


\section{Location and Geologic Map}

Tono Area
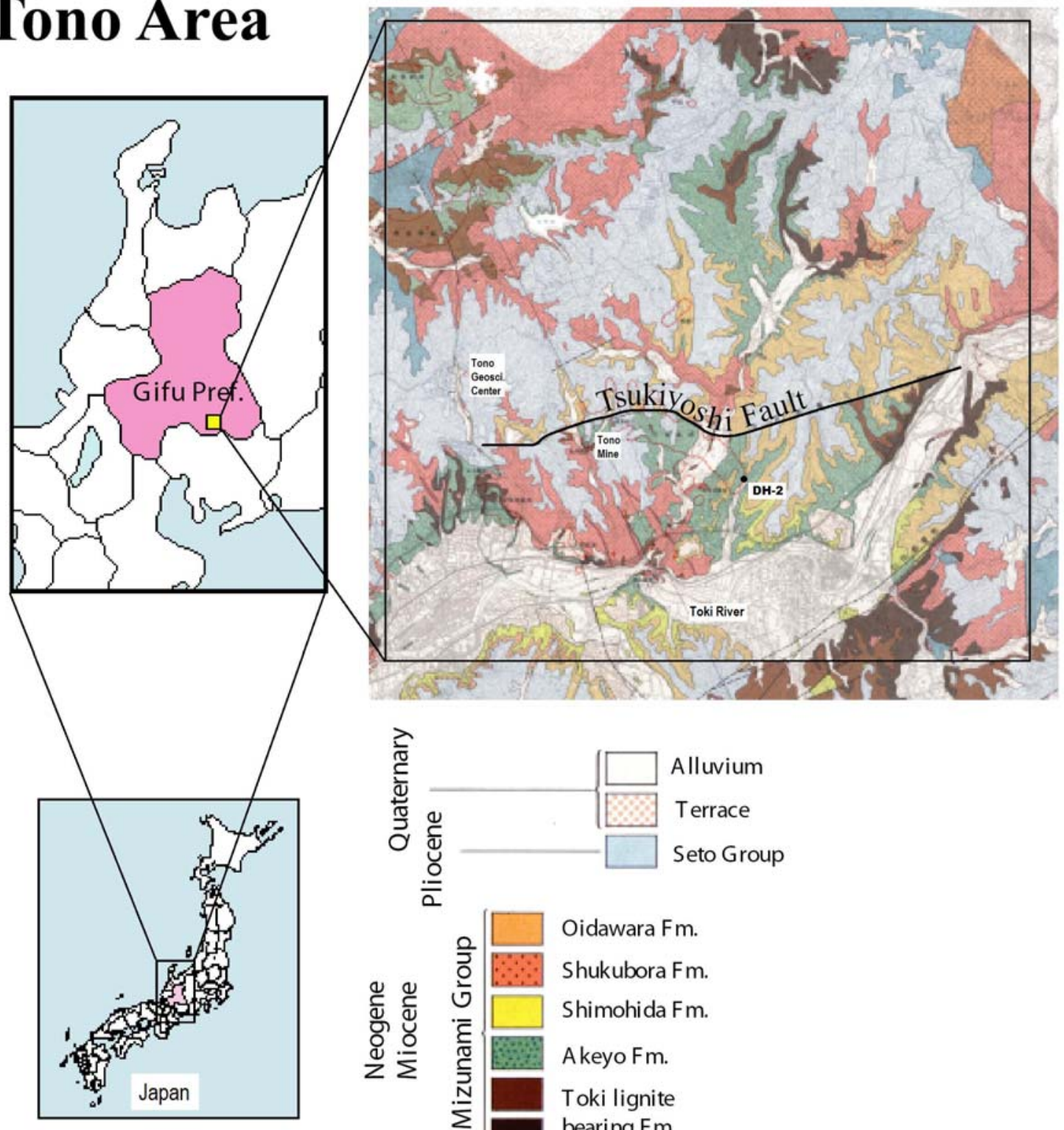

Z

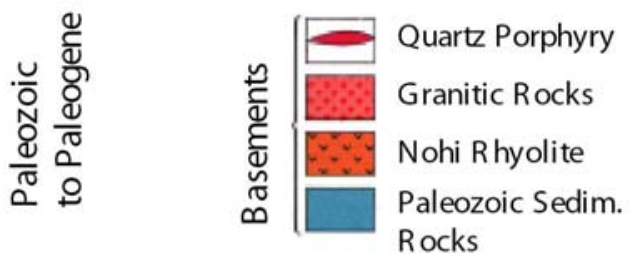

Figure 2. Site map of the Tono area, showing well DH-2. 


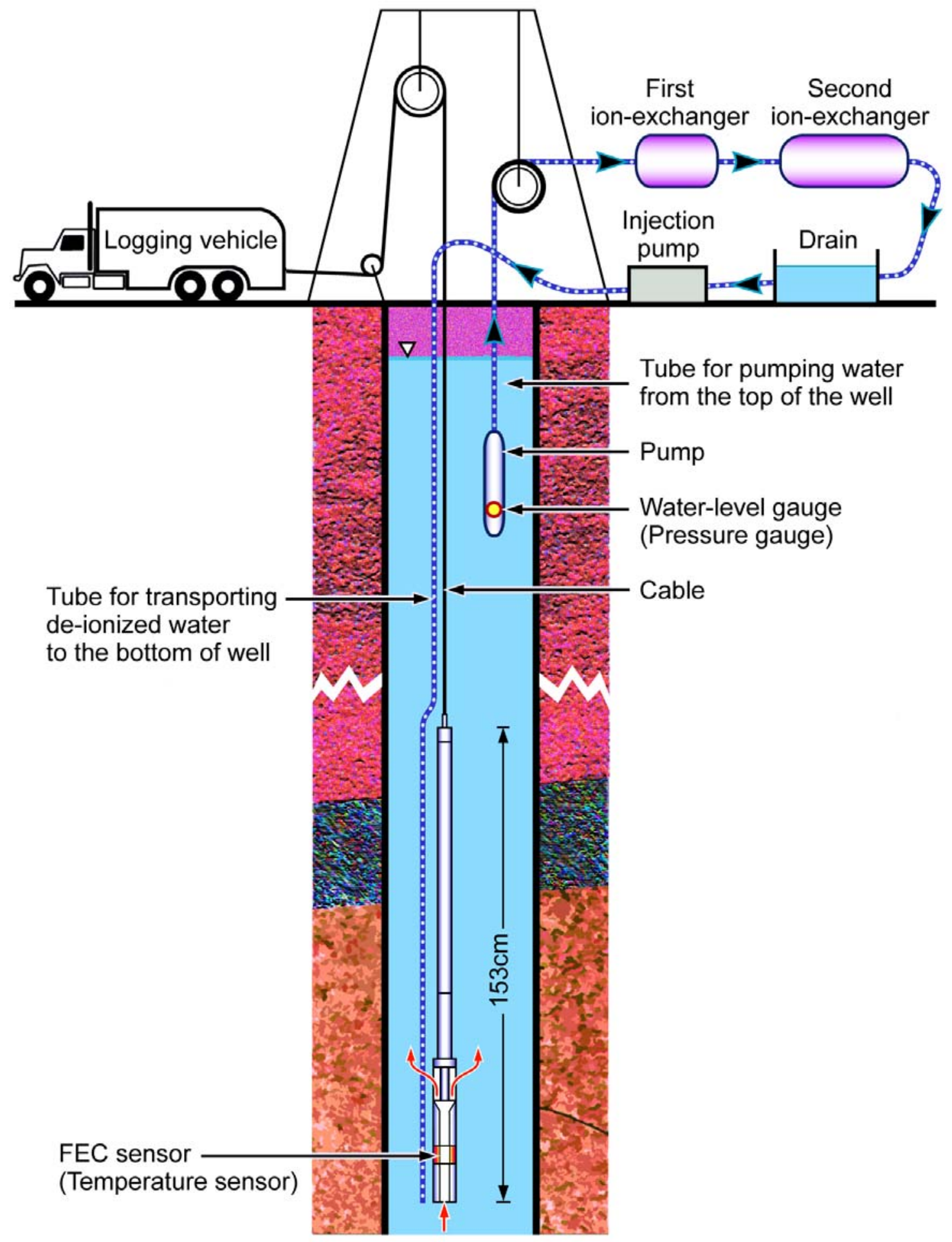

Figure 3. Field logging setup for replacement of wellbore fluid by de-ionized water. During logging operations, the setup is the same except that the tube for transporting de-ionized water to the bottom of the well is absent. 

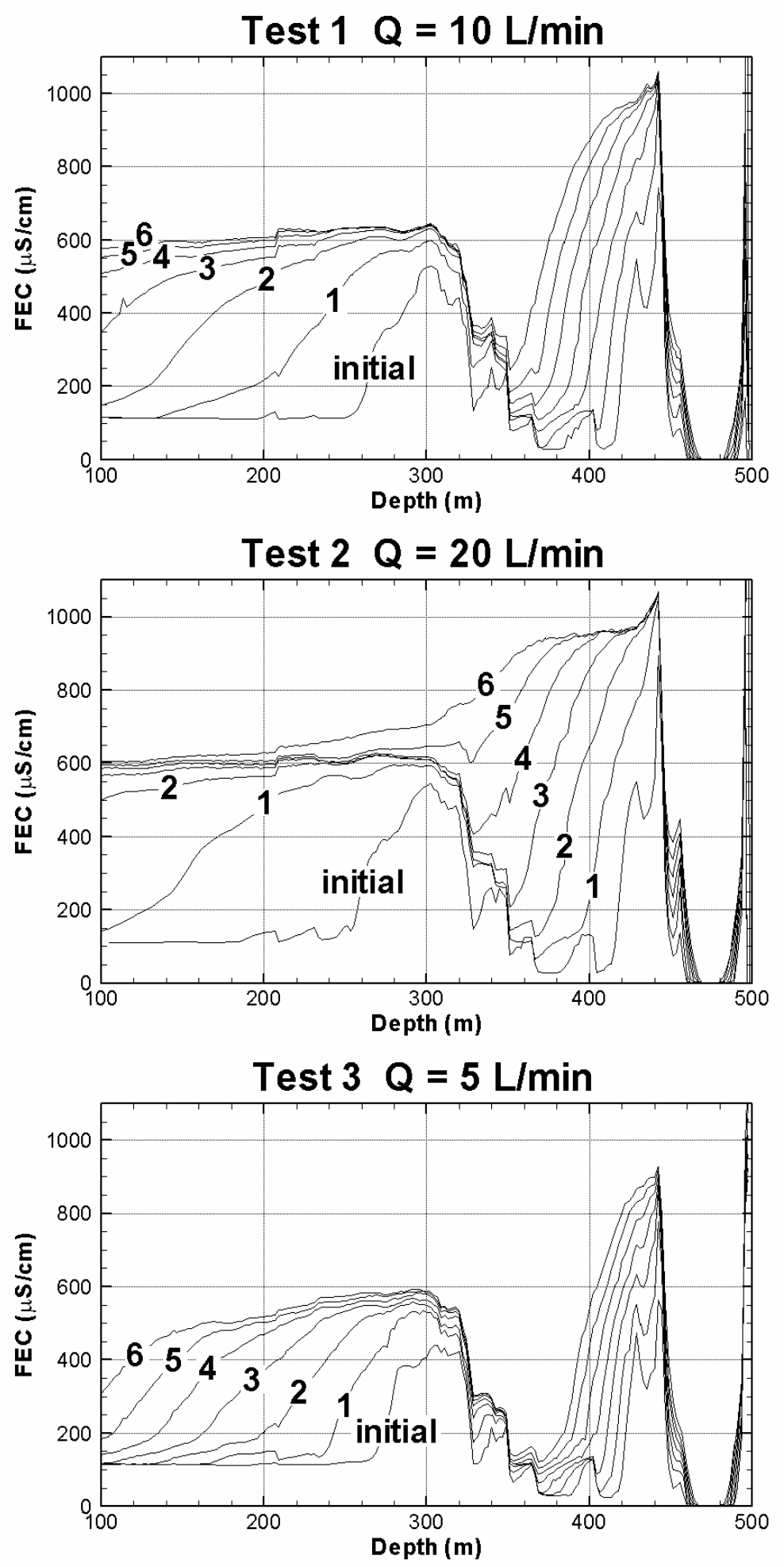

Figure 4. Observed FEC profiles for the three tests, at $Q=10,20$, and $5 \mathrm{~L} / \mathrm{min}$. FEC values have been temperature-corrected. The profile labeled 'initial' is taken as soon as pumping commences. Numbers identify profile start time in hours. 

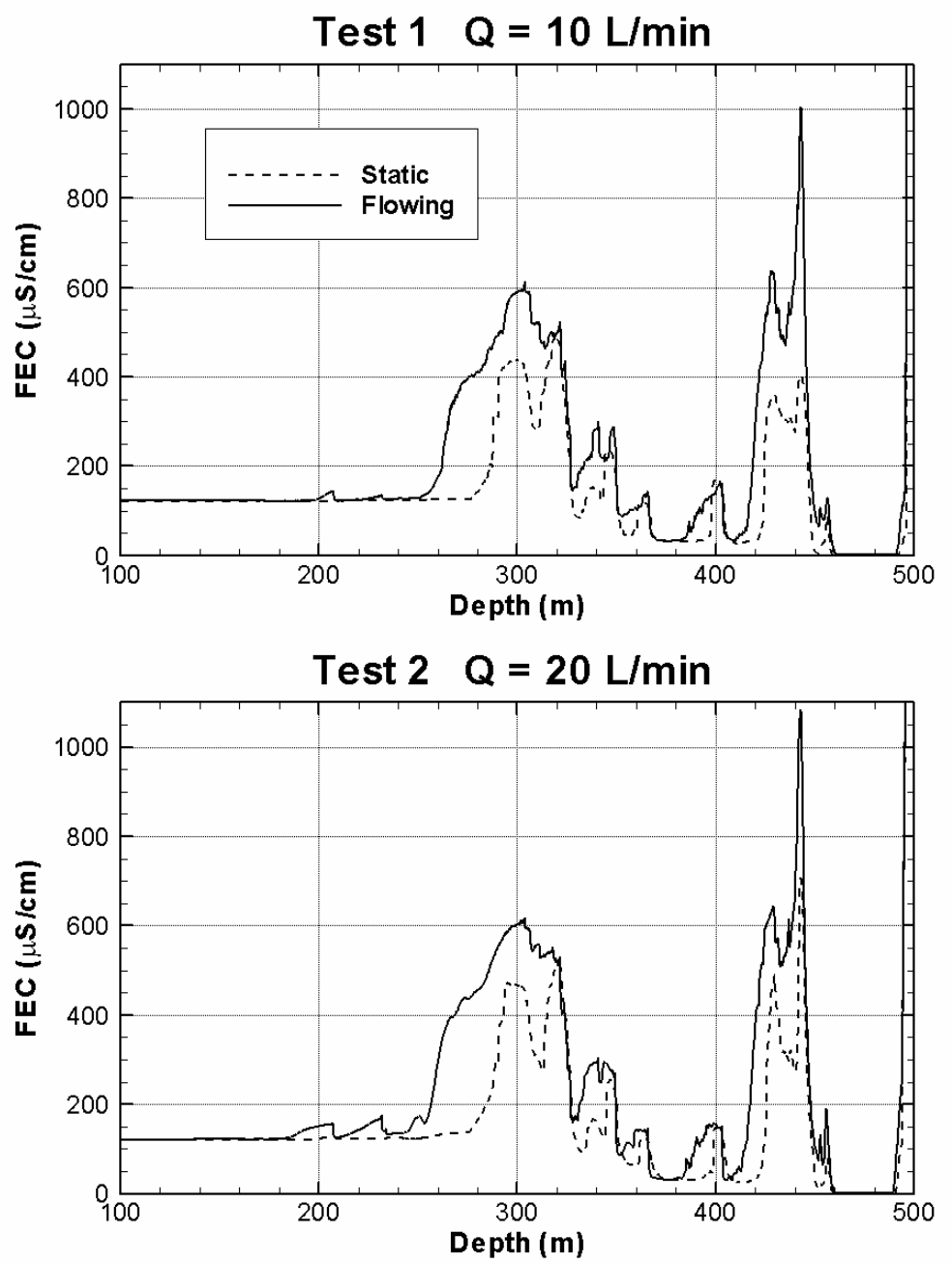

Test $3 Q=5 \mathrm{~L} / \mathrm{min}$

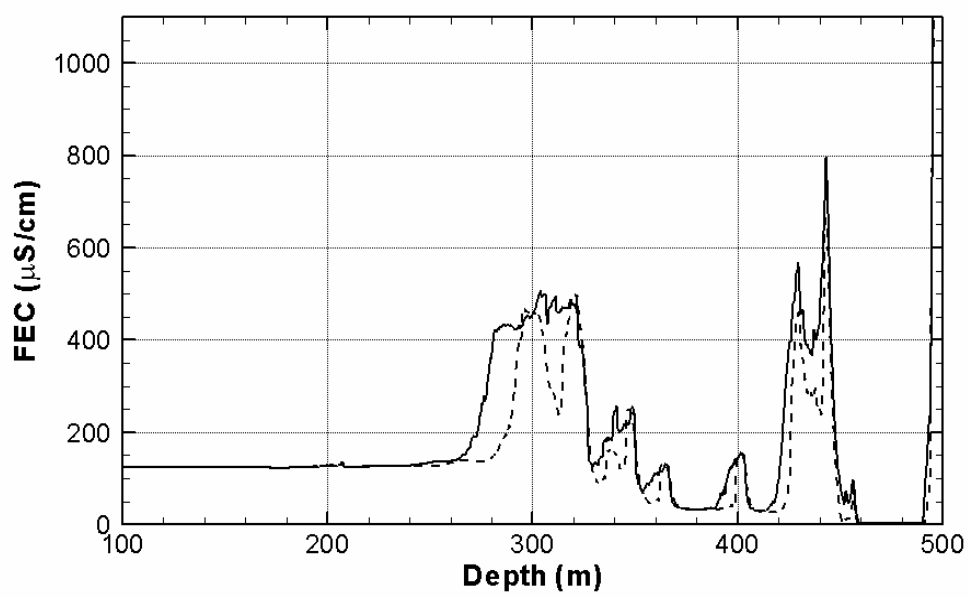

Figure 5. Early-time observed FEC data for the three tests. The line labeled "Static" is the zeropumping FEC profile collected after the borehole water has been replaced by de-ionized water and before pumping begins. The line labeled "Flowing" represents the first FEC profile measured just after pumping started (after about 4-7 minutes of pumping). 

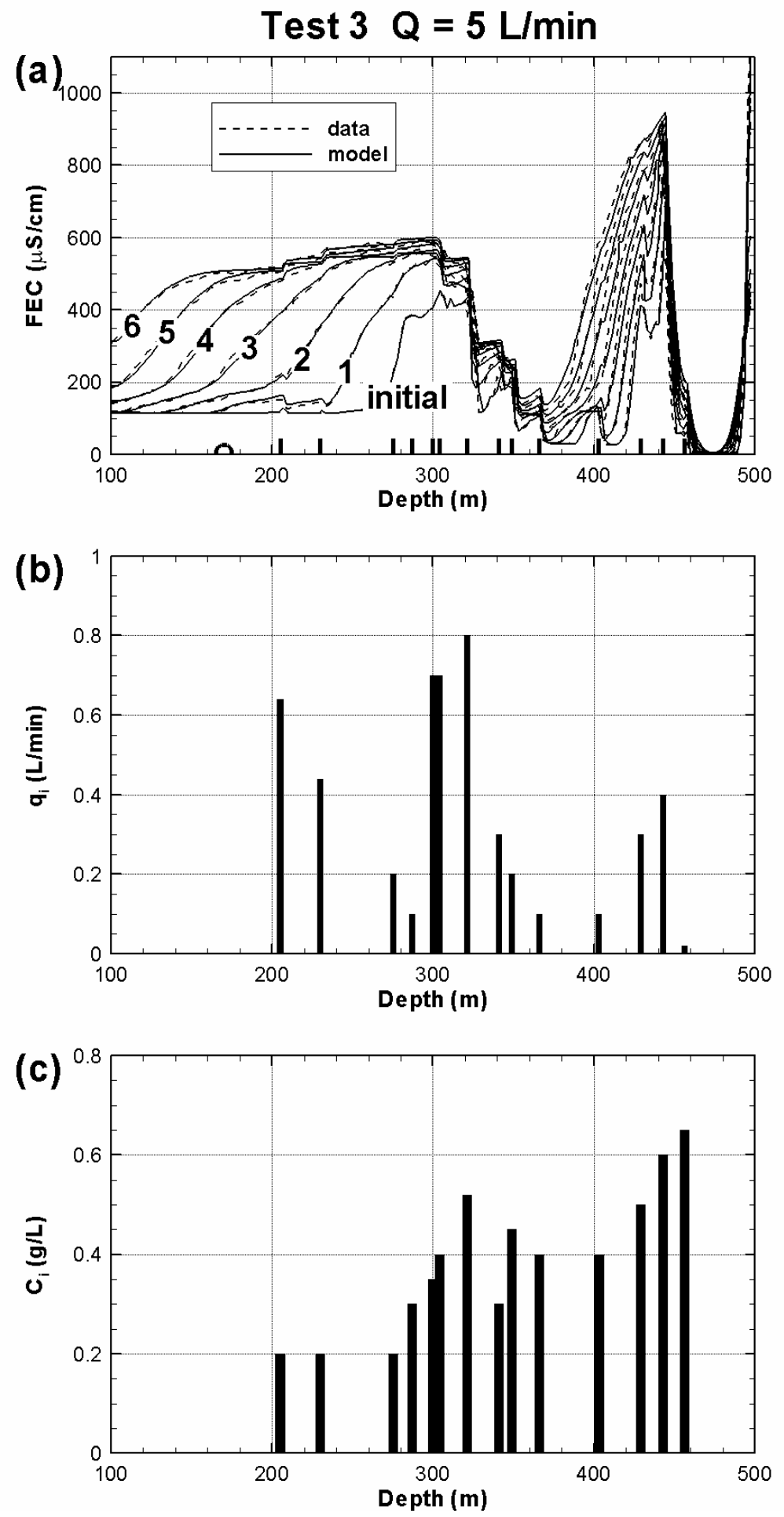

Figure 6. Independent analysis of Test 3 ( $Q=5 \mathrm{~L} / \mathrm{min})$ : (a) Best FEC match between model and data, (b) inflow rates at feed points, and (c) salinity at feed points. 


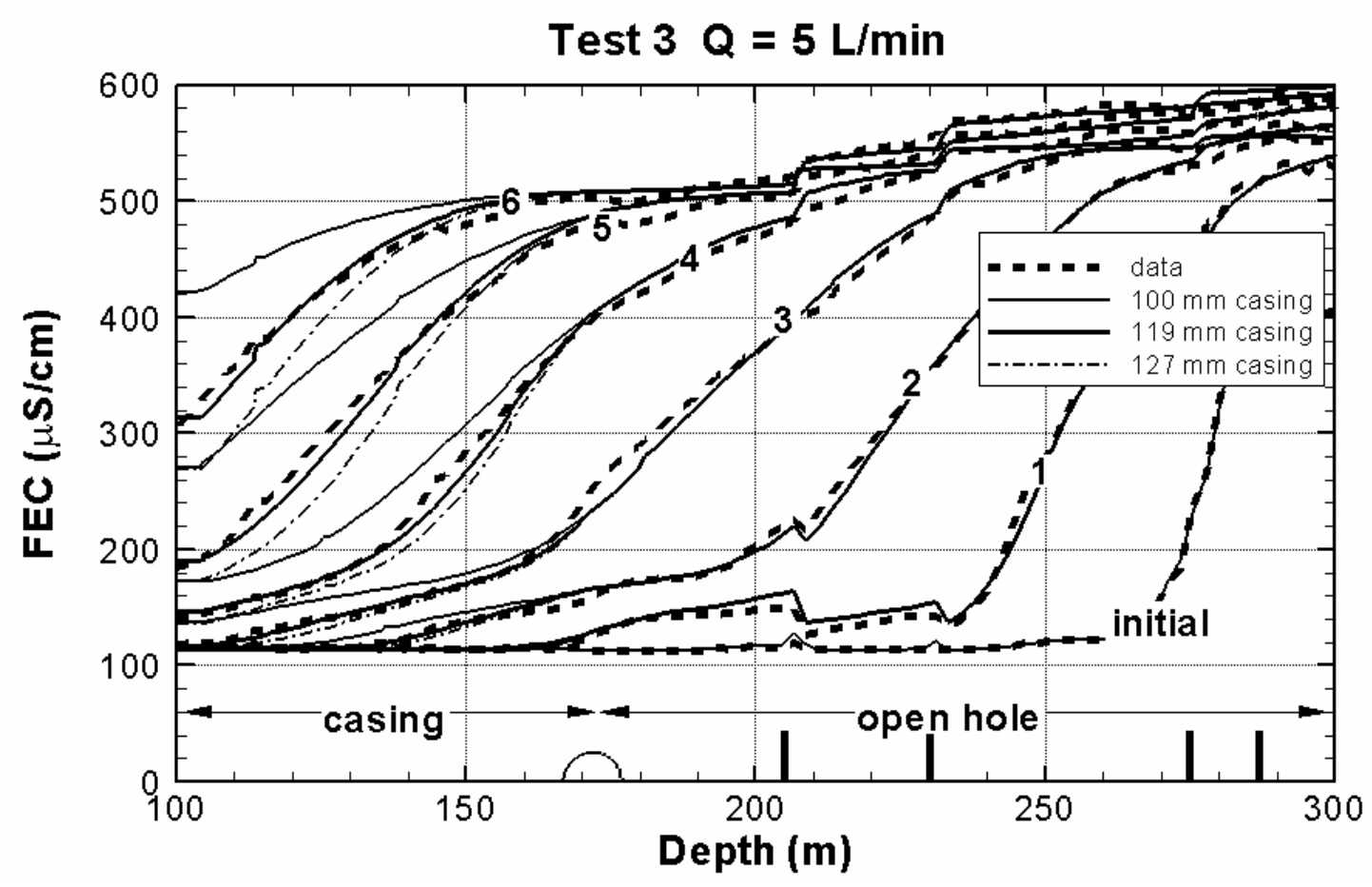

Figure 7. Sensitivity study showing effect of borehole diameter change at $170 \mathrm{~m}$ on FEC profiles. 


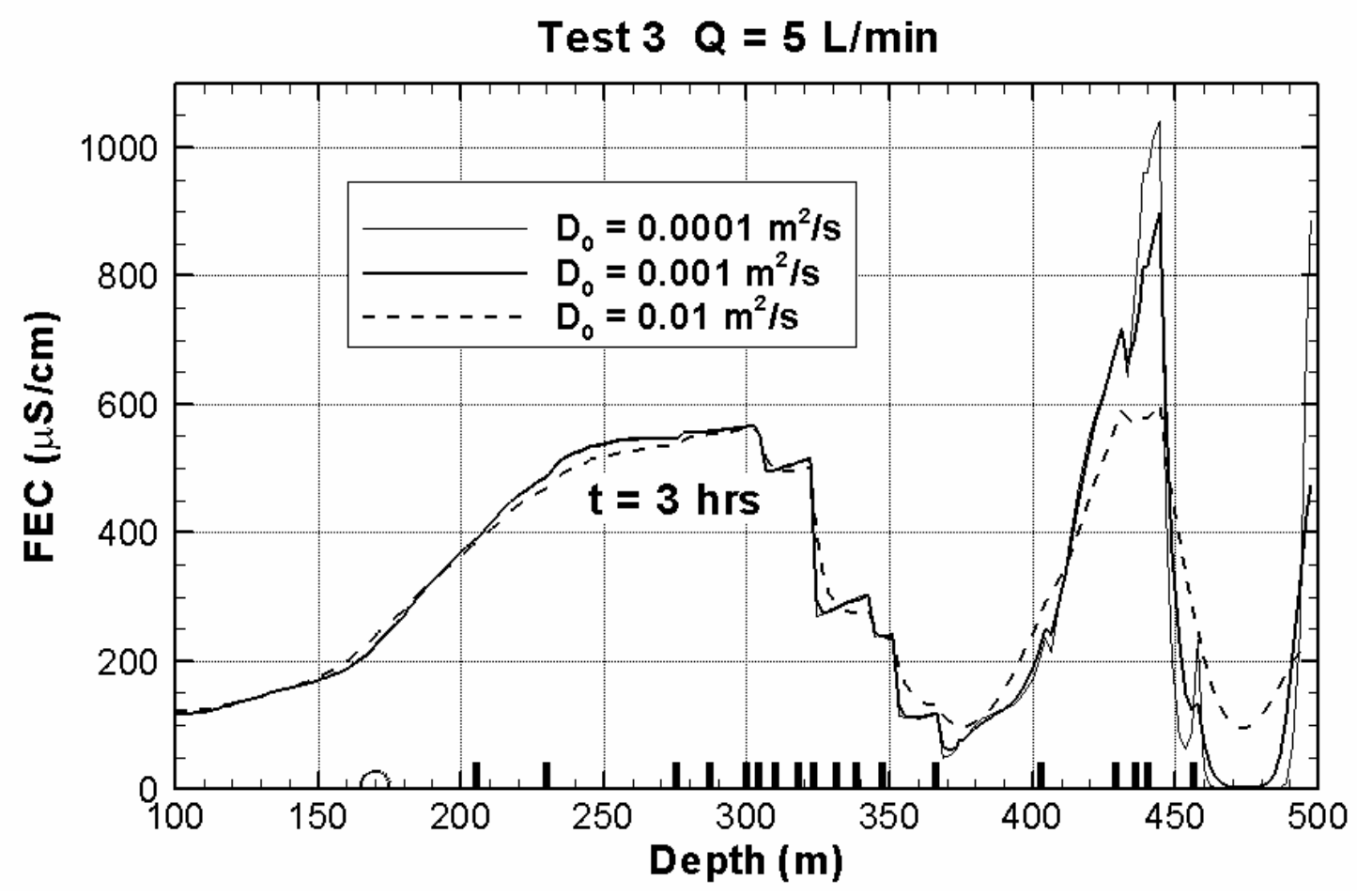

Figure 8. Sensitivity study showing effect of dispersivity on an FEC profile. 

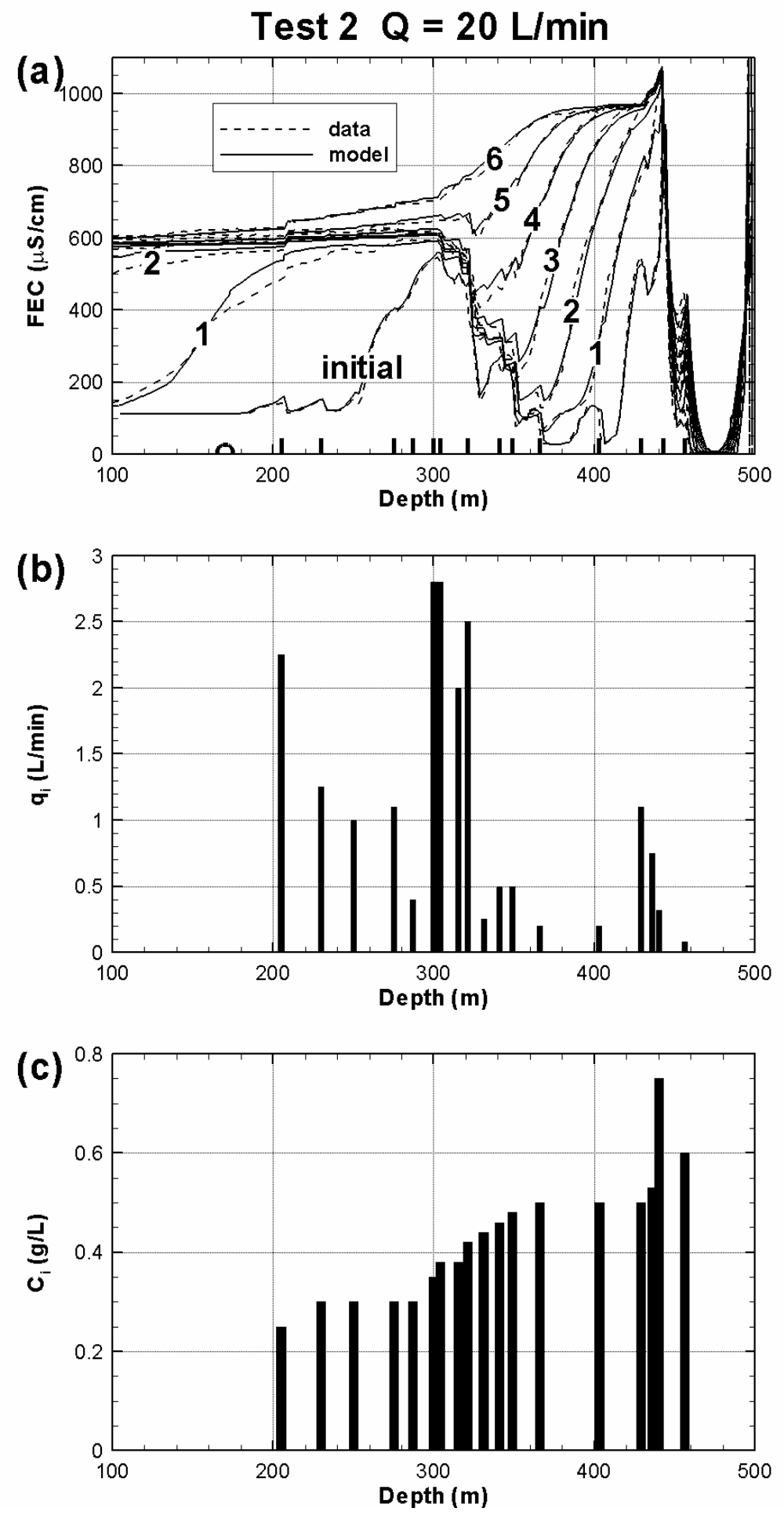

Figure 9. Independent analysis of Test $2(Q=20 \mathrm{~L} / \mathrm{min})$ : (a) best FEC match between model and data, (b) inflow rates at feed points, and (c) salinity at feed points. 

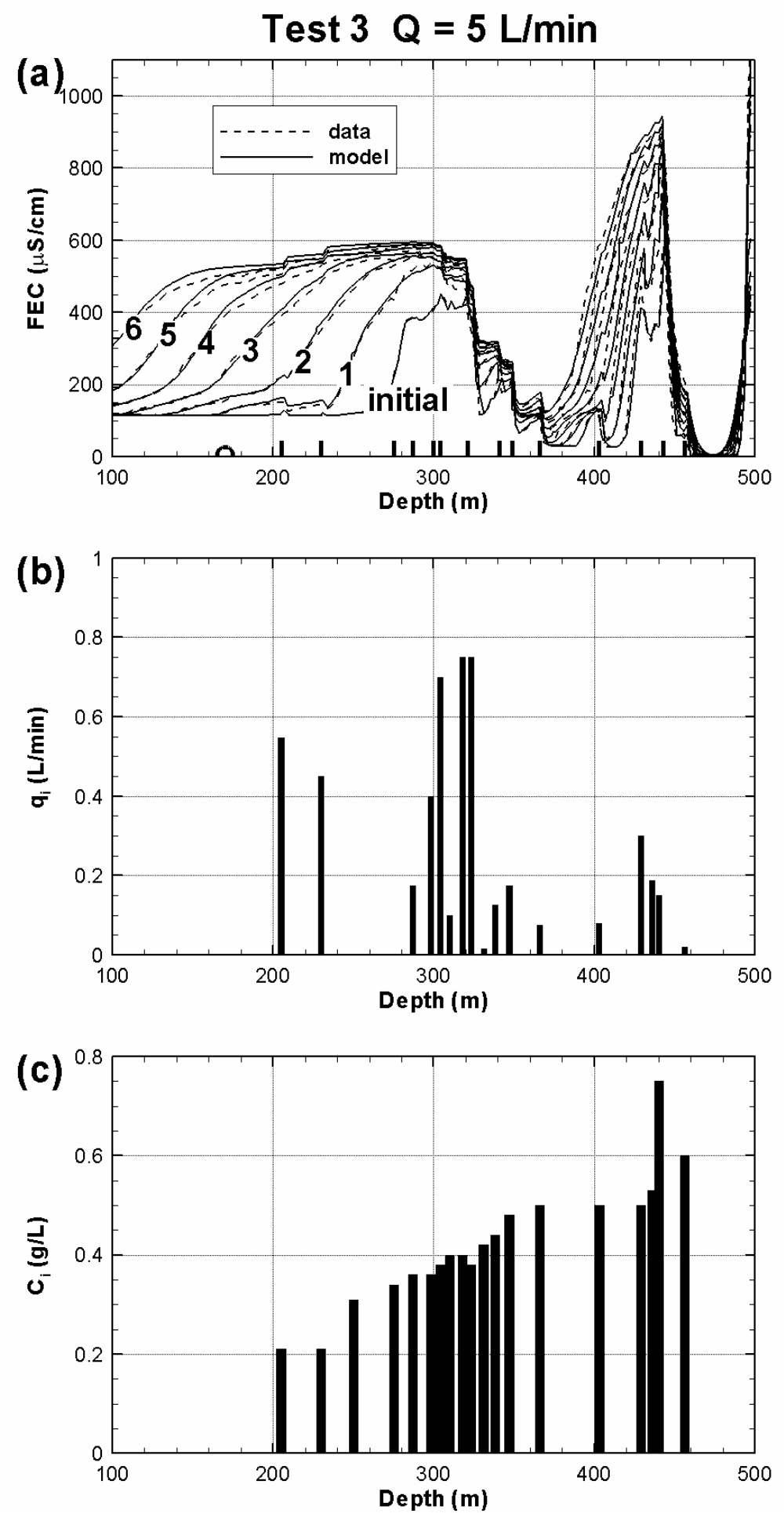

Figure 10. Updated analysis of Test $3(Q=5 \mathrm{~L} / \mathrm{min})$, using the same feed-point salinities for Tests 2 and 3: (a) best FEC match between model and data, (b) inflow rates at feed points and (c) salinities at feed points. 

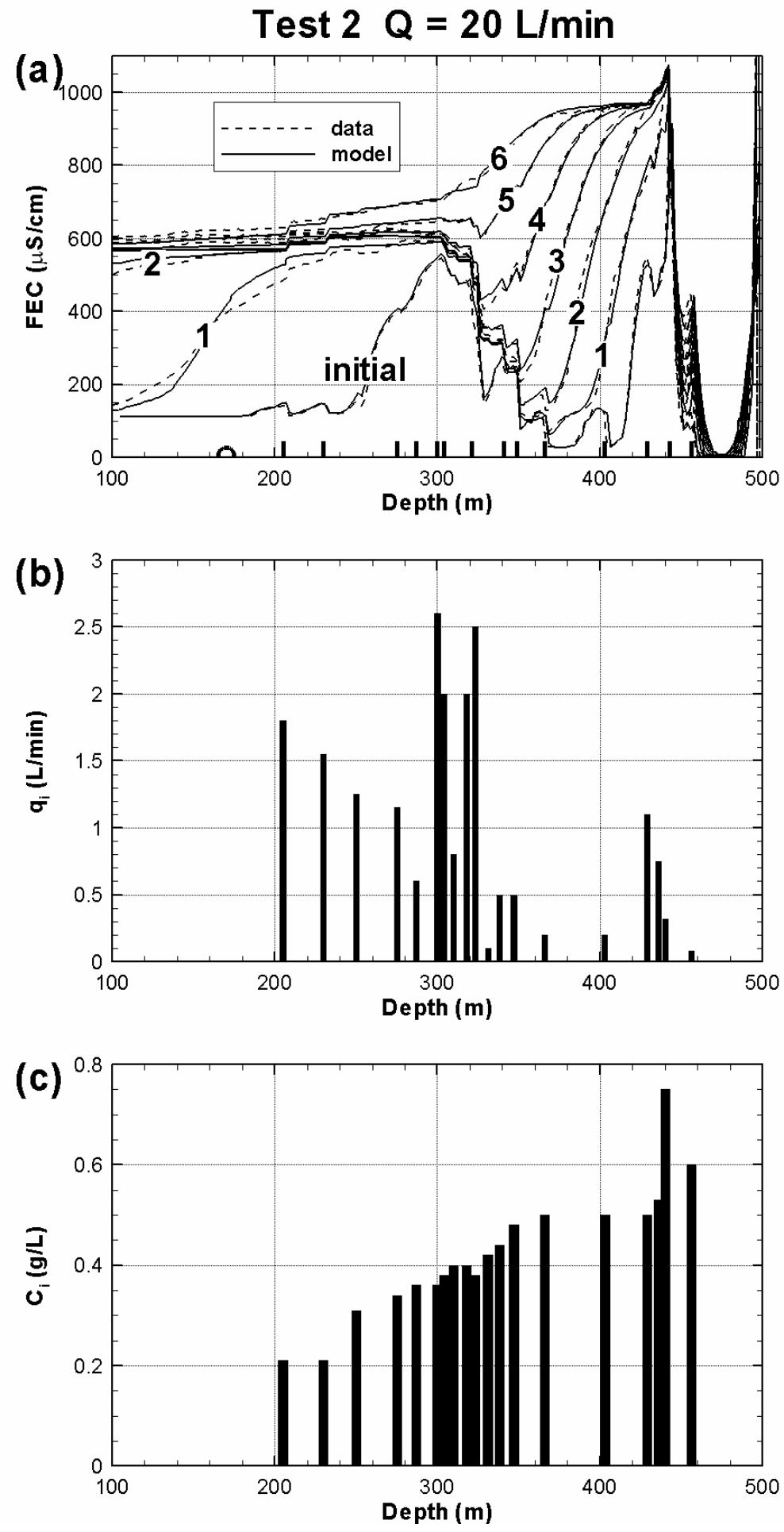

Figure 11. Updated analysis of Test $2(Q=20 \mathrm{~L} / \mathrm{min})$, using the same feed-point salinities for Tests 2 and 3: (a) best FEC match between model and data, (b) inflow rates at feed points, and (c) salinities at feed points. 


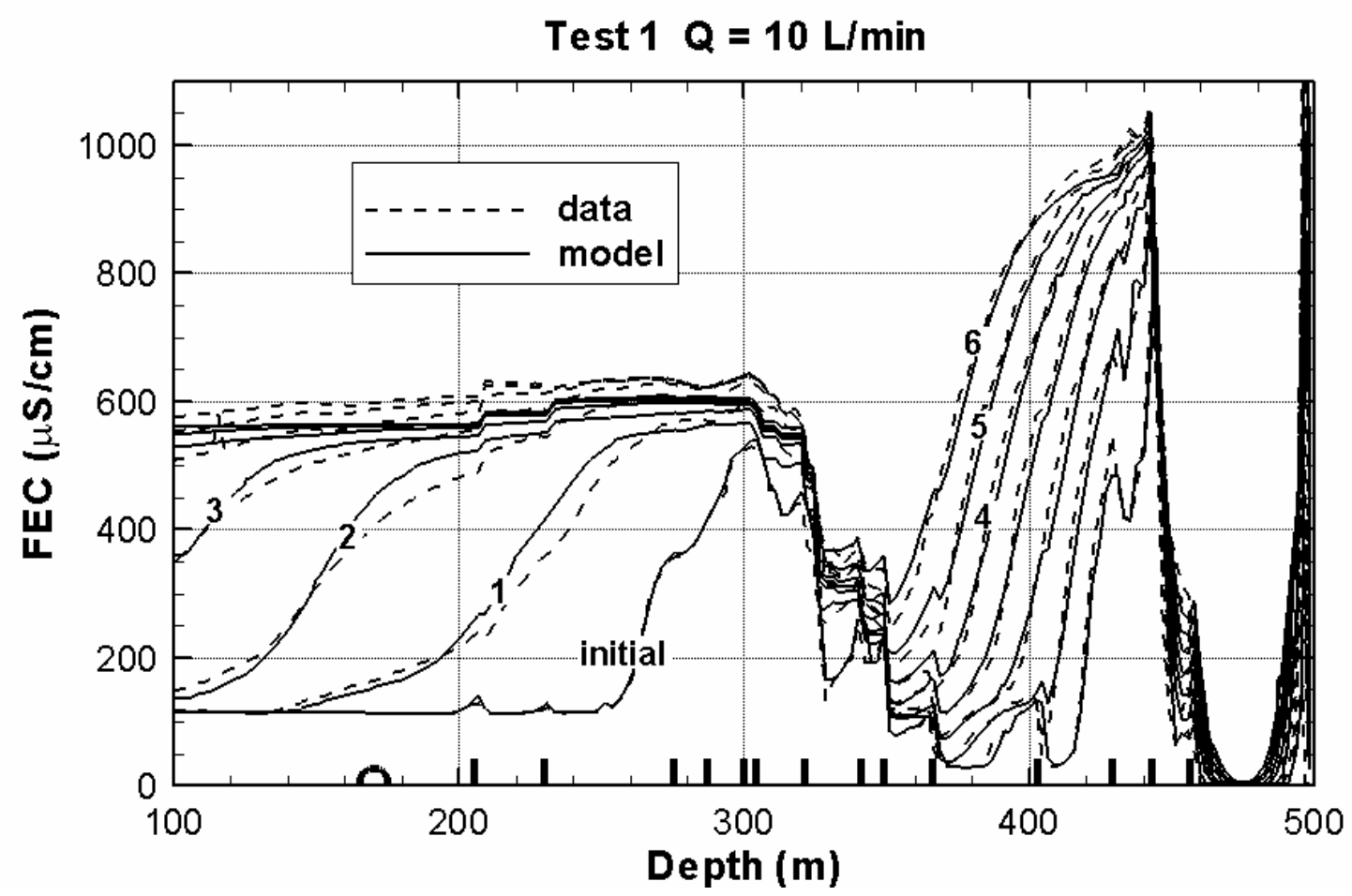

Figure 12. Comparison between observed and modeled FEC profiles for Test $1(Q=10 \mathrm{~L} / \mathrm{min})$, for a model using feed-point strengths and salinities inferred from Test 2 and Test 3. 

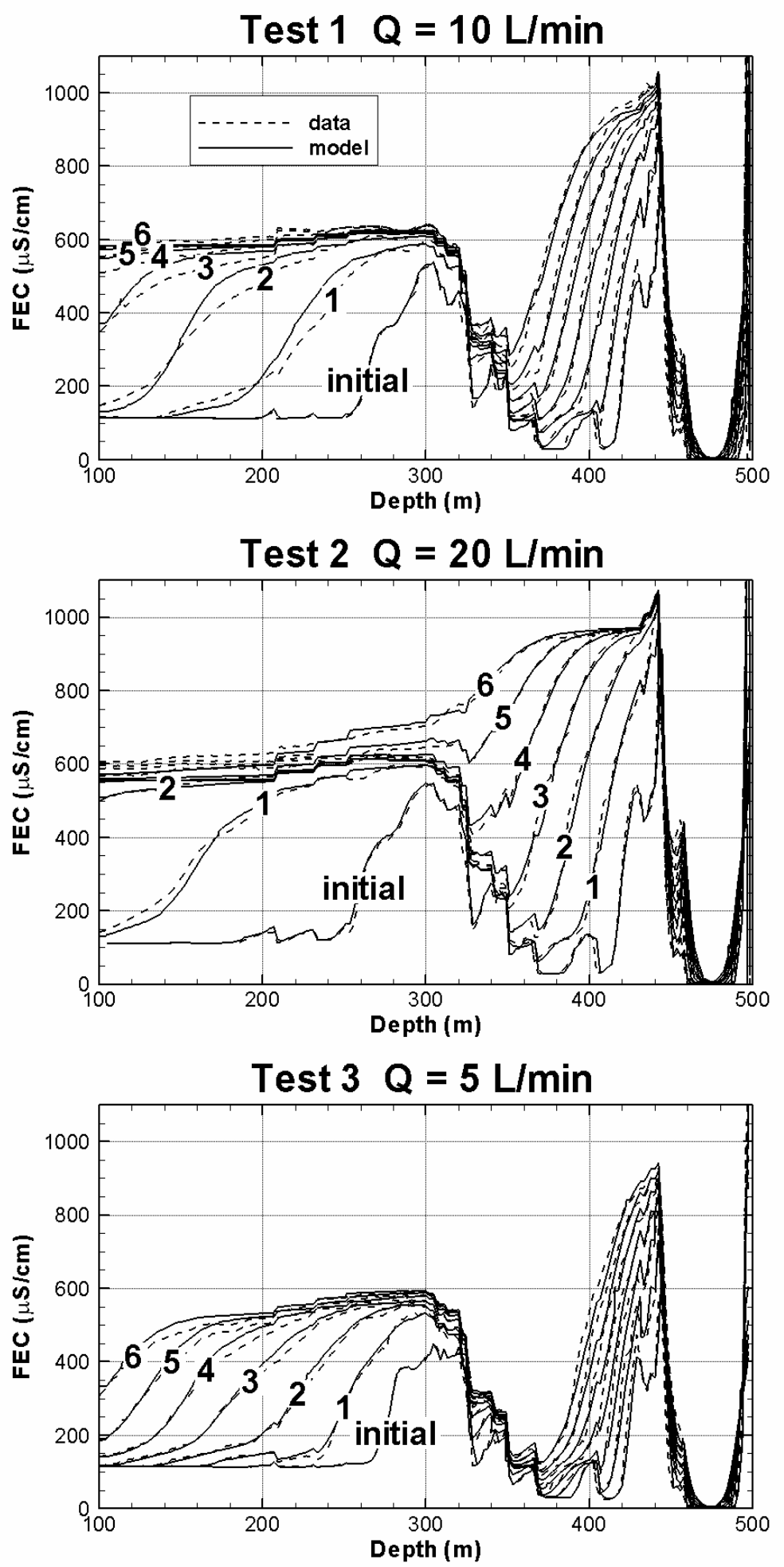

Figure 13. Best-match FEC profiles for a combined analysis of Tests 1, 2, and 3, using the same feed-point salinities for each test. 
(a)

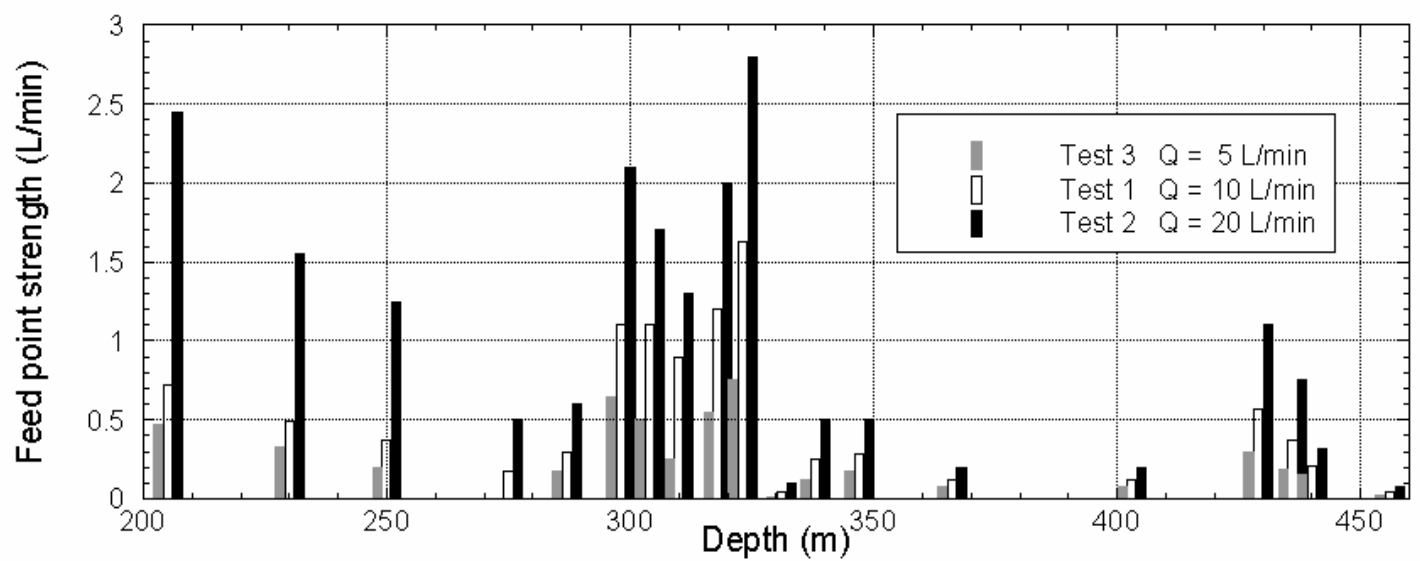

(b)

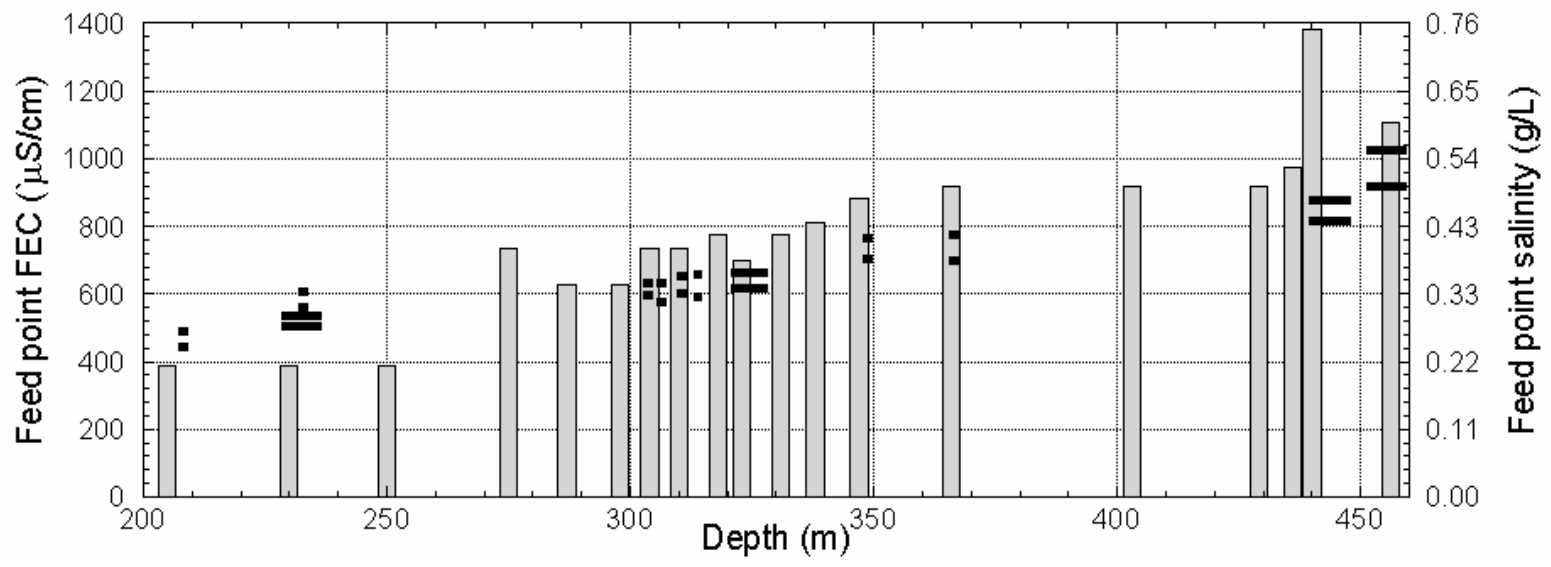

Figure 14. (a) Feed-point strengths for all three tests, and (b) FEC or salinity of feed points (same for all tests). The black bars show independent information on FEC values in isolated wellbore intervals (Section 5.3), which was not used in the present analysis. 

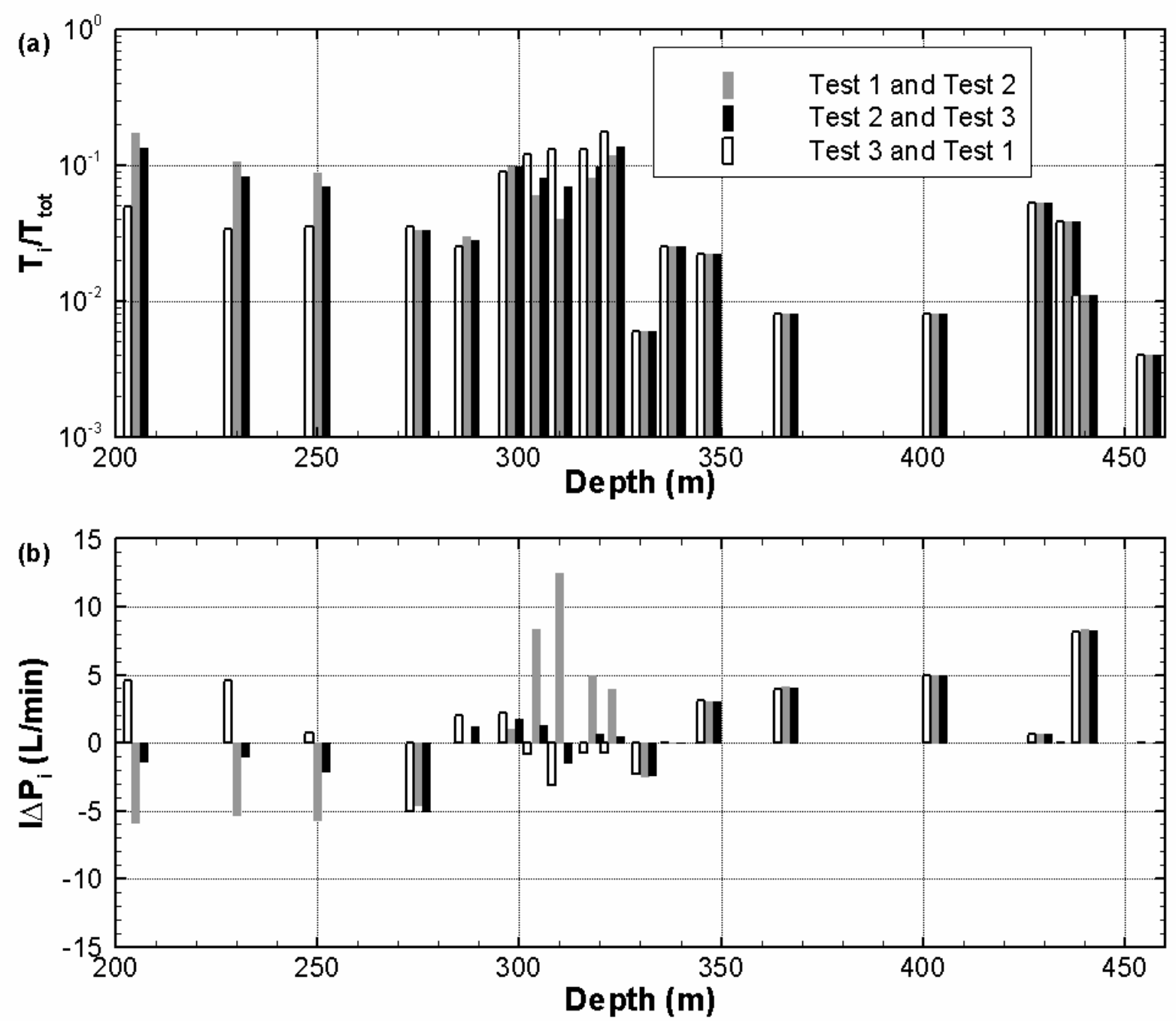

Figure 15. Results obtained for three combinations of the three tests: (a) feed-point transmissivities divided by total transmissivity, from Equation (1); and (b) productivity index times pressure head difference, from Equation (4). 


\section{Zero-pumping FEC profiles}

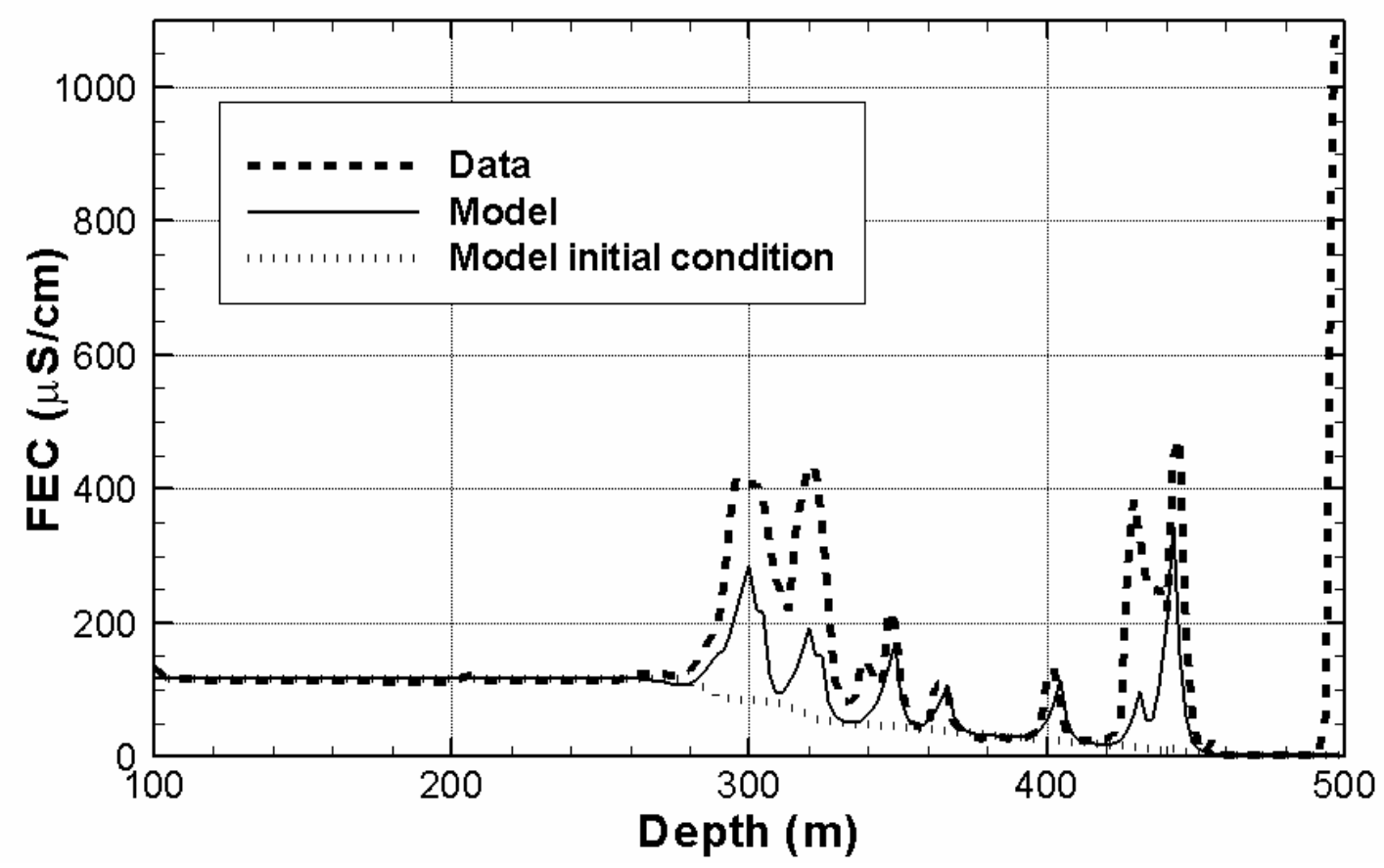

Figure 16. Modeled and observed FEC peaks produced by internal wellbore flow prior to Test 3. 
Composite Log in DH-2 Borehole (1:2000)

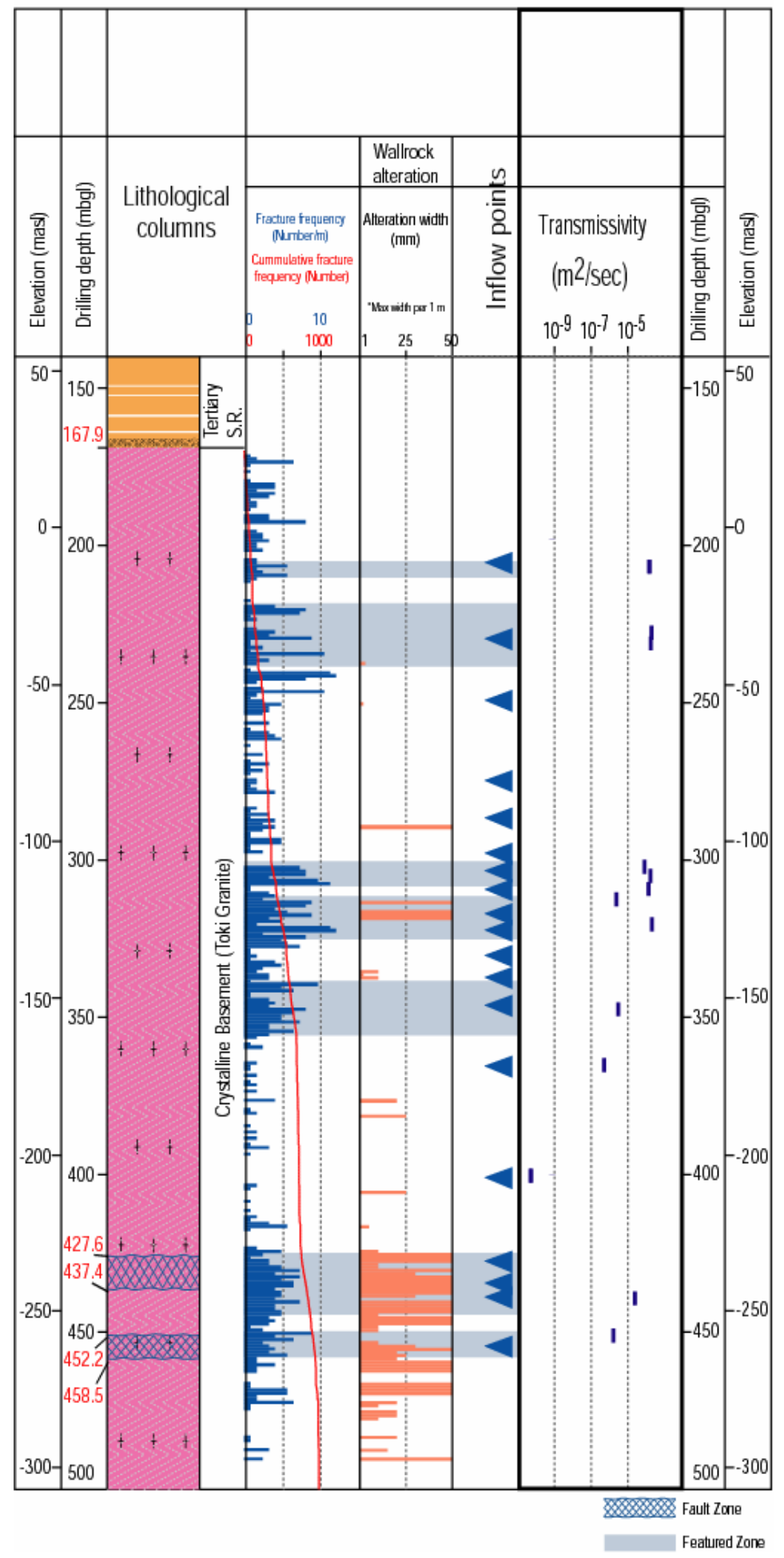

Figure 17. Overview of well DH-2 borehole investigations. The column labeled "inflow points" shows flowing FEC logging results. 


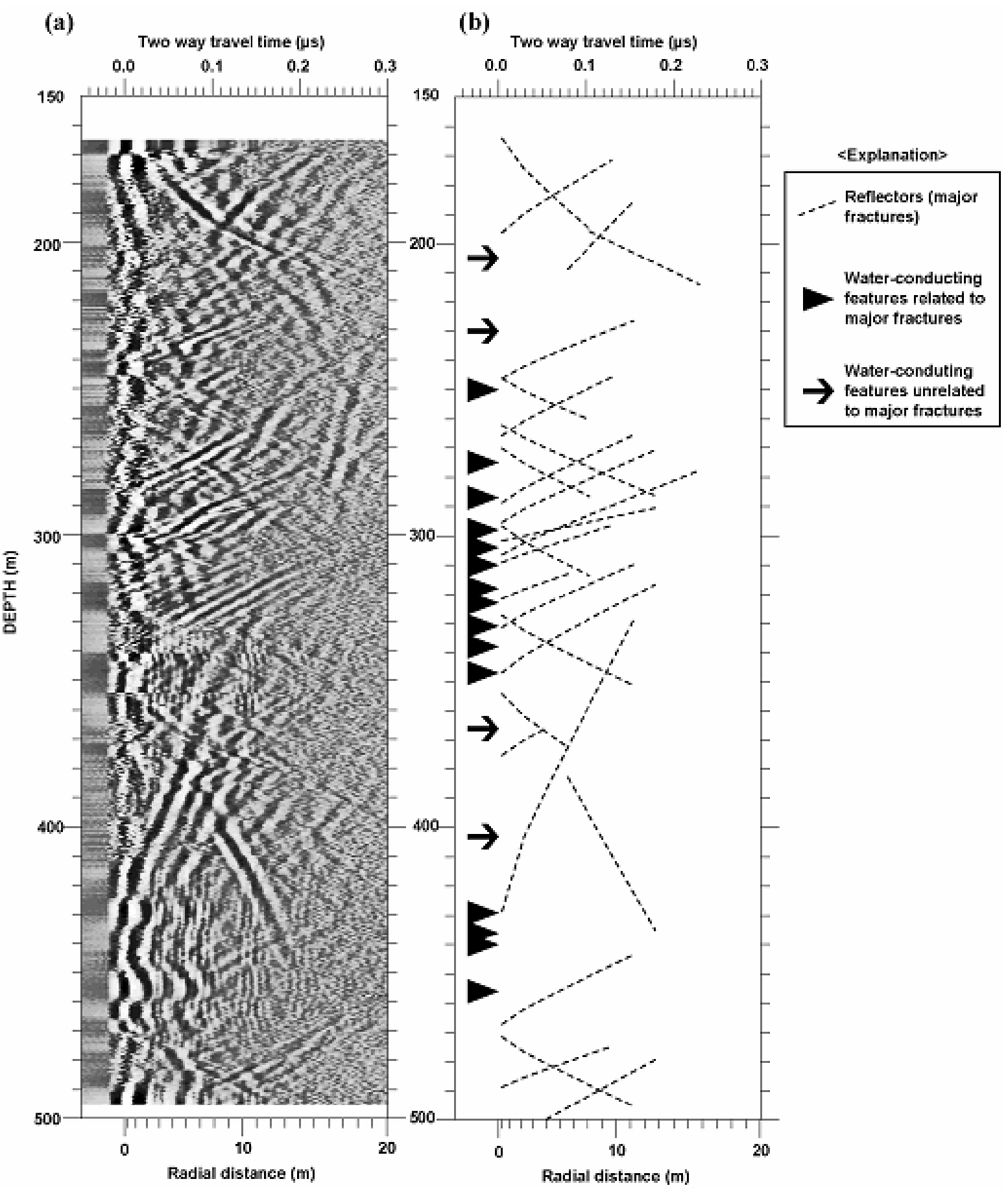

Figure 18. (a) Borehole radar log; and (b) interpreted reflectors with the locations of waterconducting features identified by flowing FEC logging. 